OPEN ACCESS

Edited by:

Buka Samten,

The University of Texas Health Science Center at Tyler, United States

Reviewed by: Meraj Alam Khan, Hospital for Sick Children, Canada Hongfei Duan, Capital Medical University, China

${ }^{*}$ Correspondence:

Catherine W. M. Ong

Catherine_wm_ong@nuhs.edu.sg

Specialty section: This article was submitted to Microbial Immunology, a section of the journal Frontiers in Immunology

Received: 04 October 2021 Accepted: 20 December 2021

Published: 12 January 2022

Citation:

Poh XY, Loh FK, Friedland JS and Ong CWM (2022) NeutrophilMediated Immunopathology and Matrix Metalloproteinases in Central Nervous System - Tuberculosis.

Front. Immunol. 12:788976. doi: 10.3389/fimmu.2021.788976

\section{Neutrophil-Mediated Immunopathology and Matrix Metalloproteinases in Central Nervous System - Tuberculosis}

\author{
Xuan Ying Poh ${ }^{1}$, Fei Kean Loh ${ }^{1}$, Jon S. Friedland ${ }^{2}$ and Catherine W. M. Ong ${ }^{1,3,4^{*}}$ \\ 1 Infectious Diseases Translational Research Programme, Department of Medicine, Yong Loo Lin School of Medicine, \\ National University of Singapore, Singapore, Singapore, 2 Institute for Infection and Immunity, St George's, University of \\ London, London, United Kingdom, ${ }^{3}$ Division of Infectious Diseases, Department of Medicine, National University Hospital, \\ Singapore, Singapore, ${ }^{4}$ Institute for Health Innovation and Technology (iHealthtech), National University of Singapore, \\ Singapore, Singapore
}

Tuberculosis (TB) remains one of the leading infectious killers in the world, infecting approximately a quarter of the world's population with the causative organism Mycobacterium tuberculosis (M. tb). Central nervous system tuberculosis (CNS-TB) is the most severe form of TB, with high mortality and residual neurological sequelae even with effective TB treatment. In CNS-TB, recruited neutrophils infiltrate into the brain to carry out its antimicrobial functions of degranulation, phagocytosis and NETosis. However, neutrophils also mediate inflammation, tissue destruction and immunopathology in the CNS. Neutrophils release key mediators including matrix metalloproteinase (MMPs) which degrade brain extracellular matrix (ECM), tumor necrosis factor (TNF)- $\alpha$ which may drive inflammation, reactive oxygen species (ROS) that drive cellular necrosis and neutrophil extracellular traps (NETs), interacting with platelets to form thrombi that may lead to ischemic stroke. Host-directed therapies (HDTs) targeting these key mediators are potentially exciting, but currently remain of unproven effectiveness. This article reviews the key role of neutrophils and neutrophilderived mediators in driving CNS-TB immunopathology.

Keywords: tuberculosis, central nervous system tuberculosis, neutrophils, matrix metalloproteinases, stroke, hostdirected therapy

\section{INTRODUCTION}

The global tuberculosis (TB) incidence remains in epidemic proportions, with an estimated 10 million new TB cases and 1.4 million TB deaths in 2019 (1). Central nervous system tuberculosis (CNS-TB), which accounts for a minimum 1-2\% of all TB disease and 5-10\% of all extra-pulmonary TB disease, is the most devastating manifestation of TB with high mortality and neurological morbidity (2). CNS-TB is almost certainly under-diagnosed and under-reported. CNS-TB encompasses three clinical-pathological forms: tuberculous meningitis (TBM), tuberculomas, and tuberculous brain abscess (3). TBM is the most severe manifestation of CNS-TB, with most 
untreated TBM patients dying within 5-8 weeks of disease onset (4). The pathogenesis of CNS-TB, is believed to originate from the lung, where $M$. $t b$ primarily infects, followed by lymphohematogenous dissemination and crossing the blood-brain barrier (BBB) to the brain, causing CNS-TB (5). During M. $t b$ infection, a complex interplay between host immune cells and $M$. $t b$ virulence factors determines whether the mycobacteria can be contained or progress to clinical TB disease. However, the underlying mechanisms of CNS-TB immunopathology are not fully understood.

Neutrophils are increasingly recognized as key mediators of TB immunopathology. Necrotizing granulomas containing neutrophils and neutrophil influx at the site of infection are hallmarks of active TB disease in humans (6-8). The presence of neutrophils in human CNS tuberculomas further highlight their role in this disease (9). There is accumulating evidence that neutrophil-derived mediators including matrix metalloproteinase-9 (MMP-9) and tumor necrosis factor- $\alpha$ (TNF- $\alpha$ ) result in immunopathology in CNS-TB (10-13). Neutrophils may also crosstalk with other immune cells such as macrophages to upregulate cytokine secretion (14), while their interactions with activated platelets may result in thrombosis, leading to the occurrence of ischemic stroke $(15,16)$. In this review, we discuss the diverse roles of neutrophils in driving CNS-TB immunopathology, highlighting key neutrophil mediators including matrix metalloproteinases. We summarize the current research on adjunctive therapies in CNS-TB, such as steroids, aspirin and anti-TNF- $\alpha$ and discuss future potential therapies to improve outcomes of this disease.

\section{EPIDEMIOLOGY OF CNS-TB}

The incidence of extra-pulmonary TB has increased in recent years since the onset of human immunodeficiency virus (HIV) infection and increased immigration from $\mathrm{TB}$ endemic regions (17). The exact global incidence of CNS-TB is unknown, given the diagnostic challenges and lack of microbiological confirmation in many suspected CNS-TB cases, which results in under-reporting (18). Regional studies have documented prevalence rates of TBM between $0.9-2.2 \%$ of all TB cases (1922), and affluent countries like Canada and the United States of America are similarly afflicted $(23,24)$. The risk factors for CNSTB include young age (25) and immunocompromised individuals such as patients living with HIV/AIDS (PLHA) (26-28). PLHA are five times more likely than HIV-negative individuals to develop neurological manifestations of TB, with up to $40 \%$ of CNS-TB-HIV co-infected patients succumbing while on anti-retroviral therapy $(18,29-31)$. Not only are children at greater risk of developing CNS-TB than adults, they are also significantly more likely than adults to suffer long-term neurological sequelae $(32,33)$. While younger age and HIV coinfection were associated with microbiologically proven CNS$\mathrm{TB}$, older age was associated with increased mortality (34). Diabetes mellitus, chronic kidney failure, presence of hydrocephalus and microbiologically-confirmed CNS-TB were independent risk factors for increased mortality (19, 32, 34-37).

\section{PATHOGENESIS AND PATHOLOGY OF CNS-TB}

In the lung microenvironment, infection of alveolar macrophages by $M$. $t b$ activates an innate inflammatory immune response rapidly (38) followed by a predominantly $\mathrm{T}$ helper 1 (Th1) immune response which eventually leads to granuloma formation (39). Early in this process before the infection is contained, $M$. $t b$ filter into draining lymph nodes, and most likely enter the circulatory system through the thoracic duct into the subclavian vein (40). A low level of $M$. $t b$ may subsequently disseminate to distant organs such as the brain. Once $M . t b$ crosses the $\mathrm{BBB}$ and enters the immune-privileged CNS, the limited local innate immune response may facilitate survival and replication of the pathogen (41). A complex interplay of host immune factors and $M$. $t b$ virulence factors determines if the infection is successfully contained or to what extent the infection progresses to clinical TB disease.

The understanding of TBM pathogenesis originated from guinea pig and rabbit studies conducted by Rich and McCordock in 1933 (42). These authors first demonstrated that the meninges could not be directly infected by the hematogenous spread of $M$. $t b$ in these animals, but rather required the direct inoculation of $M$. $t b$ into the CNS to produce TBM (42). From human post-mortem examinations, Rich and McCordock showed that in almost every TBM patient, there was a meningeal focus from which $M$. $t b$ could enter the subarachnoid space and cause meningitis (42). Subsequent studies corroborated their findings, and it became accepted that a caseating vascular focus, termed the "Rich focus", located in the meninges or adjacent to the ventricles is the key pathway for $M$. $t b$ to gain access to the subarachnoid space and cause a granulomatous infection of the meninges (43-46). The location of these foci and the ability or inability of the host immune response to control the infection determines the form of CNS-TB that develops (5). When a Rich focus in the meninges ruptures, $M$. $t b$ is released from the granulomatous lesions into the CSF, resulting in extensive inflammation and TBM (39). Separately, the enlargement of Rich foci in the brain parenchyma without rupturing gives rise to tuberculomas, thus they often occur in the absence of TBM (39). While it is widely accepted that the rupture of Rich foci causes $M$. $t b$ dissemination leading to TBM, the foci may not present in all CNS-TB manifestations. In rare cases, $M$. $t b$ infection spreads to the CNS from a site of tuberculous otitis or calvarial osteitis (3). Furthermore, histological examination of TBM brain specimens showed that most of the intraparenchymal granulomas are an extension of leptomeningeal lesions, which opposes the Rich focus hypothesis (47). We suspect that alternative $M$. $t b$ entry routes exist to spread to the CNS may not be well characterized.

CNS-TB presents as several forms of intracranial and spinal TB manifestations, with the most common being TBM, tuberculomas, and tuberculous brain abscess. TBM is the most severe manifestation of CNS-TB with highest mortality and neurological morbidity $(48,49)$. Majority of TBM patients experience non-specific symptoms such as fatigue, fever, 
malaise, anorexia, and myalgia for 2-8 weeks before the meningitic state ensues, where patients present with headache, fever, vomiting, photophobia and neck stiffness in $75 \%$ of cases (50-52). Left untreated, most TBM patients die within 5-8 weeks of disease onset (4). Common radiological features seen in TBM include basal meningeal enhancement, tuberculomas, hydrocephalus, and infarctions $(29,53)$. Although a combination of these imaging features is highly specific for TBM (95-100\%), most radiological findings by themselves lack adequate sensitivity as they may not be detected radiographically until advanced stages $(18,54-$ 56). Hydrocephalus, which is the most frequent cause of raised intracranial pressure in TBM patients, was also found to be associated with advanced stage of infection, with high morbidity and mortality $(18,57)$. Cerebral vasculitis and inflammation both of which are regulated by platelet activation result in infarcts and are the primary cause of permanent brain tissue damage in TBM (58-60).

Cranial nerve palsies occur in $25-50 \%$ of patients and can lead to vision loss if the optic nerve is involved (2). Although seizures occur in $10-15 \%$ of patients, it is more common in pediatric TBM patients (18). The severity of TBM disease can be classified into 3 grades based on modifications of the Medical Research Council staging system (Table 1) (65), which has been shown by numerous reports to have considerable prognostic value $(61,62,66)$. In HIV-negative TBM patients, mortality has been documented to be $20 \%$ at stage I, $30 \%$ at stage II, and $55 \%$ at stage III (62).

The tuberculoma is the pathological hallmark of $M . t b$ infection, and may occur with or without TBM development (39). Macroscopically, they appear as spherical, encapsulated space-occupying lesions on neuroradiology (67). While a solitary lesion is more common in CNS-TB patients, multiple tuberculomas or even up to $>100$ tuberculomas have been seen in exceptional cases (68). Most tuberculomas are up to $1 \mathrm{~cm}$ in diameter, with approximately $10 \%$ between $1-3 \mathrm{~cm}$, but may reach sizes of up to $8 \mathrm{~cm}$ (69). Microscopically, a tuberculoma is characterized by a granulomatous region, comprising of epithelioid cells, Langerhans giant cells and lymphocytes, and often a central area of caseating necrosis (29).

Tuberculous brain abscess is a rare manifestation of CNS-TB. Its appearance is more similar to pyogenic brain abscess than to tuberculomas and generally larger in size than tuberculomas. These brain abscesses may be unilocular or multilocular, and is characterized by cavity formation with central area of pus containing viable bacteria $(70,71)$.

Analysis of the pathology in TBM patients reveal three types of granulomas found mainly in the leptomeninges. Non- necrotizing granuloma comprises of activated macrophages, lymphocytes and plasma cells, while necrotizing gummatous granuloma containing reticulin fibers are present in the necrosis central area with intact neutrophils (47). The other necrotizing abscess-type of granuloma has similar presentation to tuberculous brain abscess, which consists of pus with high concentration of neutrophils $(71,72)$. The abundance of neutrophils indicates their important role in CNS-TB.

\section{CELLULAR RESPONSES IN CNS-TB}

The brain is protected from blood-borne pathogens by the BBB, which consists of brain microvascular endothelial cells joined by tight junctions, astrocyte end-feet ensheathing the capillary, and pericytes embedded in the basement membrane (Figure 1) (73). Two mechanisms by which $M$. $t b$ crosses the protective BBB have been proposed (74-76). In vitro and animal models have demonstrated that $M$. $t b$ is capable of invading and traversing brain endothelial cells directly by modulating their actin rearrangement $(75,76)$. The $M$. $t b$ gene $p k n D(R v 0931 c)$ was recently identified as a critical virulence factor that facilitates bacterial adhesion to laminin-1 and -2 on brain endothelial cells (77). Another potential route of CNS entry is the "Trojan horse" mechanism, whereby $M$. $t b$ is trafficked across the BBB in infected macrophages and neutrophils (74). Following the breach of the BBB, resident CNS-specific cells such as microglia are activated and leukocytes will infiltrate into the CNS to induce the inflammatory response.

\section{Crosstalk Between Neutrophils and Other Immune Cells}

Leukocytes such as neutrophils and monocytes interact with endothelial adhesion molecules to transmigrate across the BBB. We have shown that conditioned media from monocytes infected with $M$. $t b$ (CoMtb)-stimulation of a BBB cellular model significantly upregulated endothelial adhesion molecules intercellular adhesion molecule 1 (ICAM-1), vascular cell adhesion molecule 1 (VCAM-1), P-Selectin and E-Selectin, which resulted in increased transmigration of monocytes and neutrophils across a BBB model (78).

TNF- $\alpha$ plays an immune-regulatory role in the infiltration of leukocytes in CNS-TB. M. $t b$-infected TNF-knockout $\left(\mathrm{TNF}^{-/}\right.$) mice showed acute ventriculitis characterized by neutrophil infiltrates extending into the periventricular tissue of the brain,

TABLE 1 | British medical research council clinical criteria for staging TBM.

\begin{tabular}{|c|c|c|}
\hline $\begin{array}{l}\text { Stage/ } \\
\text { grade }\end{array}$ & Classic criterion & Contemporary criterion \\
\hline I & Fully conscious and no focal deficits & Alert and oriented without focal neurological deficits \\
\hline II & Conscious but with inattention, confusion, lethargy, and focal neurological signs & Glasgow coma score of $14-11$ or 15 with focal neurological deficits \\
\hline III & $\begin{array}{l}\text { Stuporous or comatose, multiple cranial nerve palsies, or complete hemiparesis or } \\
\text { paralysis }\end{array}$ & $\begin{array}{l}\text { Glasgow coma score of } 10 \text { or less, with or without focal neurological } \\
\text { deficits }\end{array}$ \\
\hline
\end{tabular}

Adapted from (61-64). 

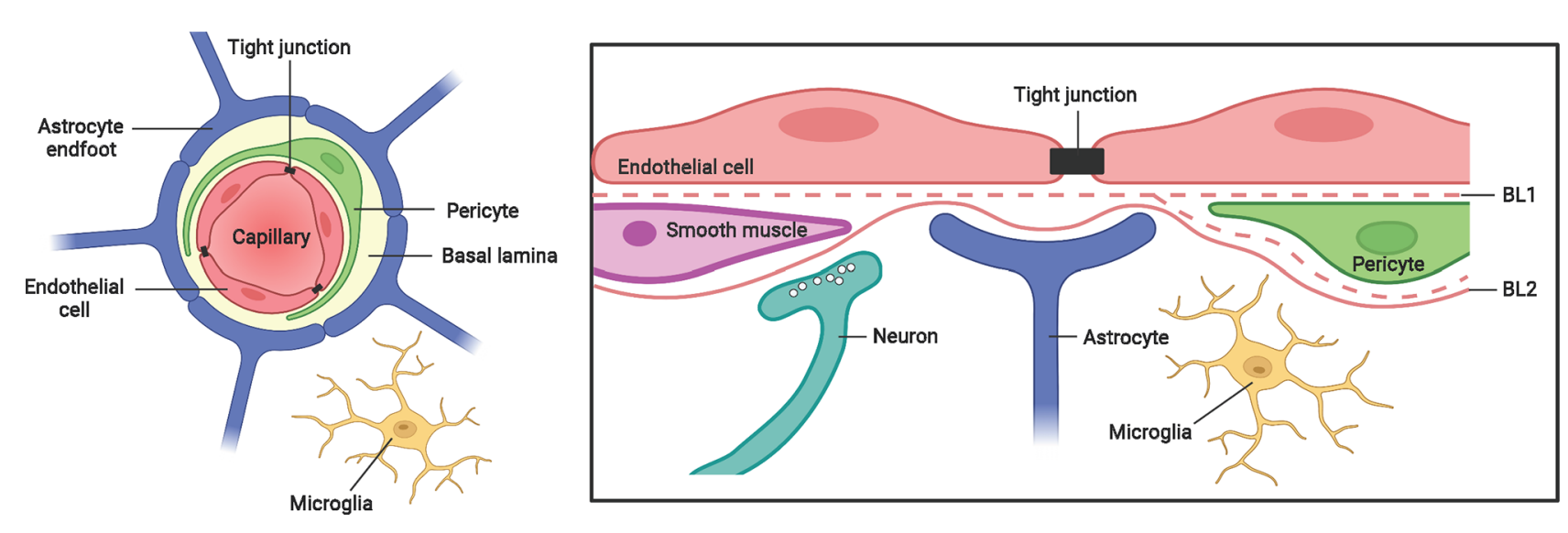

FIGURE 1 | The blood-brain-barrier structure and cellular composition. The BBB is a highly complex structure, made up of brain microvascular endothelial cells, pericytes, astrocytes and a non-cellular component - the basal lamina. Tight junctions between brain endothelial cells maintain the integrity and permeability of brain microvessels. Both the endothelial cells and pericytes are enclosed by, and contribute to the perivascular extracellular matrix (basal lamina 1, BL1), which is different in composition from the extracellular matrix of the glial end feet (BL2) bounding the brain parenchyma. Figure created with Biorender.com.

while a mixture of lymphocytes and neutrophils were observed at the choroid plexus (79). Compared to wild type mice, $M$. $t b$ infected $\mathrm{TNF}^{-/-}$mice showed increased macrophages and dendritic cell (DC) recruitment, with upregulation of chemokines macrophage inflammatory protein-1 $\alpha$ (MIP-1 $\alpha$ ), monocyte chemoattractant protein-1 (MCP-1) and Regulated upon Activation Normal T Cell Expressed and Presumably Secreted (RANTES) (79). In CNS-TB, neutrophils may engage in complex multi-directional interactions with other immune cells such as monocytes, macrophages, dendritic cells and $\mathrm{T}$ lymphocytes. Several studies have evaluated the interaction of neutrophils and monocytes in CNS-TB. Monocyte-neutrophil networks resulted in MMP-9 upregulation which may be further upregulated by hypoxia (80), and lead to type IV collagen and tight junction protein (TJP) breakdown with an associated increase in neutrophil and monocyte transmigration across the $\mathrm{BBB}(78,79)$. Using an in vitro $\mathrm{BBB}$ model, we elucidated the molecular mechanisms by which monocyte-neutrophil networks drive MMP-9 secretion, and found mitogen activated protein kinase (MAPK) and phosphatidylinositide-3 kinase (PI3K)-Akt pathways and the transcription factor nuclear factor kappa B (NF-kB) to regulate neutrophil MMP-9 secretion (9).

As part of the innate host immune response in CNS-TB, neutrophils interact with CNS resident microglia and infiltrated macrophages. In early CNS-TB, both neutrophils and macrophages infiltrate across the BBB into the CNS $(78,79)$. They are rapidly activated, proliferate and secrete cytokines, which further drive the accumulation and activation of other immune cells (81). M. tb-infected neutrophils showed upregulation of MCP-1, which is essential for recruiting macrophages $(82,83)$. Moreover, Braian et al. demonstrated that macrophages produced significantly higher concentrations of cytokines IL-6, TNF- $\alpha$, IL- $1 \beta$ and IL-10 in response to NETs from $M$. $t b$-activated neutrophils but not phorbol myristate acetate-activated neutrophils (14), further highlighting the importance of neutrophil-macrophage interaction in $\mathrm{TB}$ infections. Conversely, $M$. $t b$-infected murine microglia secrete granulocyte-macrophage colony-stimulating factor (GM-CSF) (84), a chemoattractant that may facilitate $M$. $t b$ containment by promoting neutrophil phagocytosis (85).

Neutrophils promote activation of $\mathrm{CD}^{+} \mathrm{T}$ cells in $\mathrm{TB}$ by facilitating DC migration and antigen presentation (86). Direct M. $t b$-infected DCs showed poor migration, whereas DCs that acquired $M . t b$ through uptake of infected neutrophils exhibited unimpaired migration to prime naive $\mathrm{CD} 4^{+} \mathrm{T}$ cells and subsequently activate adaptive immunity (86), implicating the key role of neutrophils in priming the T cells. In CNS-TB, the presence of DCs was reported (79), but no study has investigated whether a similar neutrophil-DC interaction occurs. Further evidence from animal studies demonstrated direct crosstalk between neutrophils and T cells. For instance, in vivo depletion of $\mathrm{Gr} 1^{+}$neutrophils decreased accumulation of Th1 cells in the lungs of $M$. $t b$-infected mice (87). Furthermore, Blomgran et al. demonstrated that an inhibition of neutrophil apoptosis in $M$. $t b$ infected mice delayed the activation of naive $\mathrm{CD} 4^{+} \mathrm{T}$ cells (88). These studies highlight the importance of neutrophils as a bridge between the innate and adaptive immune response.

\section{NEUTROPHILS IN CNS-TB}

\section{Neutrophils Influx}

The normal brain is devoid of neutrophils, and the recruitment of circulating neutrophils into the CNS during infection is dependent on neutrophil chemoattractants. The contribution of neutrophil mediators to CNS-TB immunopathology is summarized in Figure 2. Small bioactive lipid mediators such as prostaglandin E2 (PGE2) and leukotriene B4 (LTB4) generated from arachidonic acid (AA) by cyclooxygenase 2 (COX-2) and 5-lipoxygenase (5-LO) respectively exhibit proinflammatory properties and are potent neutrophil chemoattractants (89-93). LTB4 secreted by early-recruited 


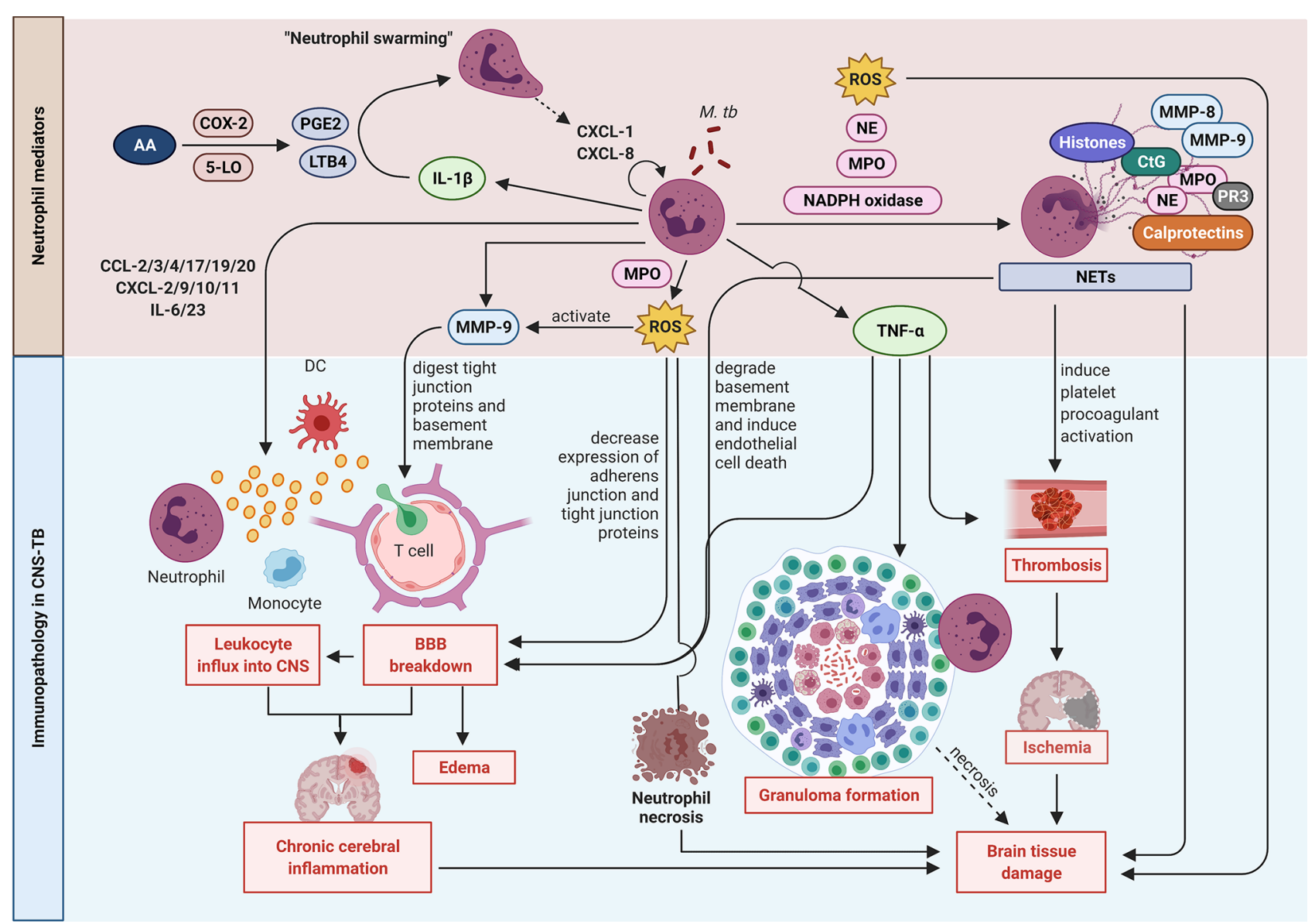

FIGURE 2 | Neutrophil mediators in CNS-TB immunopathology. Neutrophils secrete cytokines including IL-1 $\beta$ to enhance neutrophil swarming and recruitment, and TNF- $\alpha$ to promote neutrophil necrosis, granuloma formation and thrombosis leading to ischemia stroke and brain tissue damage. Neutrophils also form NETs containing destructive enzymes which can damage the brain tissue. The release of MMP-9 degrades the extracellular matrix (ECM) resulting in BBB breakdown, leukocytes influx and eventually chronic cerebral inflammation. The ROS production also mediates BBB breakdown and drives neutrophil necrosis. 5-LO: 5lipoxygenase; AA, arachidonic acid; COX-2, cyclooxygenase-2; CtG, cathepsin G; DC, dendritic cell; LTB4, leukotriene B4; MMP, matrix metalloproteinase; MPO, myeloperoxidase; M. tb, Mycobacterium tuberculosis; NE, neutrophil elastase; NETs, neutrophil extracellular traps; PGE2, prostaglandin E2; PR3, proteinase 3; ROS, reactive oxygen species; TNF- $\alpha$, tumor necrosis factor- $\alpha$. Illustration created with Biorender.com.

neutrophils function in an autocrine response to induce an exponential neutrophil influx, an effect known as "neutrophil swarming" (94, 95). In addition, LTB4 was demonstrated to induce ICAM-1 expression by vascular endothelial cells to facilitate neutrophil transmigration into the tissue (96). Treatment of $M$. $t b$-infected $\mathrm{C} 3 \mathrm{HeB} / \mathrm{FeJ}$ mice with Ibuprofen, an anti-inflammatory drug that inhibits COX-2, strongly suppressed neutrophil recruitment, ameliorated tissue pathology and improved survival, thereby providing further evidence of neutrophils contributing to immunopathology in TB disease (97).

\section{Neutrophil Cell Death - Protection Versus Pathology}

Neutrophils are the first cells to arrive at the site of $M$. $t b$ infection by migrating along a chemokine gradient formed by IL-8 (also known as CXCL-8) or keratinocyte chemoattractant
(KC) in humans or mice respectively (98). Being professional phagocytes, neutrophils rapidly engulf $M . t b$, but the fate of the infected neutrophils and whether they mediate protection or pathology in TB depends on $M$. $t b$ virulence. Human neutrophils fail to kill virulent $M$. tb in vitro due to $M$. $t b$-induced necrotic cell death, a process that was recently found to be dependent on a functional ESAT-6 secretion system 1 (ESX-1) in $M$. $t b$ and the neutrophil's own reactive oxygen species (ROS) production (Figure 3) (99, 100). Neutrophil necrosis is detrimental to the host as the release of granule proteases and antimicrobial effectors cause damage to neighboring cells and exacerbate tissue damage. In addition, subsequent removal of necrotic neutrophils and virulent $M$. tb by macrophages promote mycobacterial growth, ultimately driving these infected macrophages into necrotic cell death (99). It is likely that the consecutive cycles of infection and host cell necrosis result in TBassociated immunopathology and host tissue damage (101). 


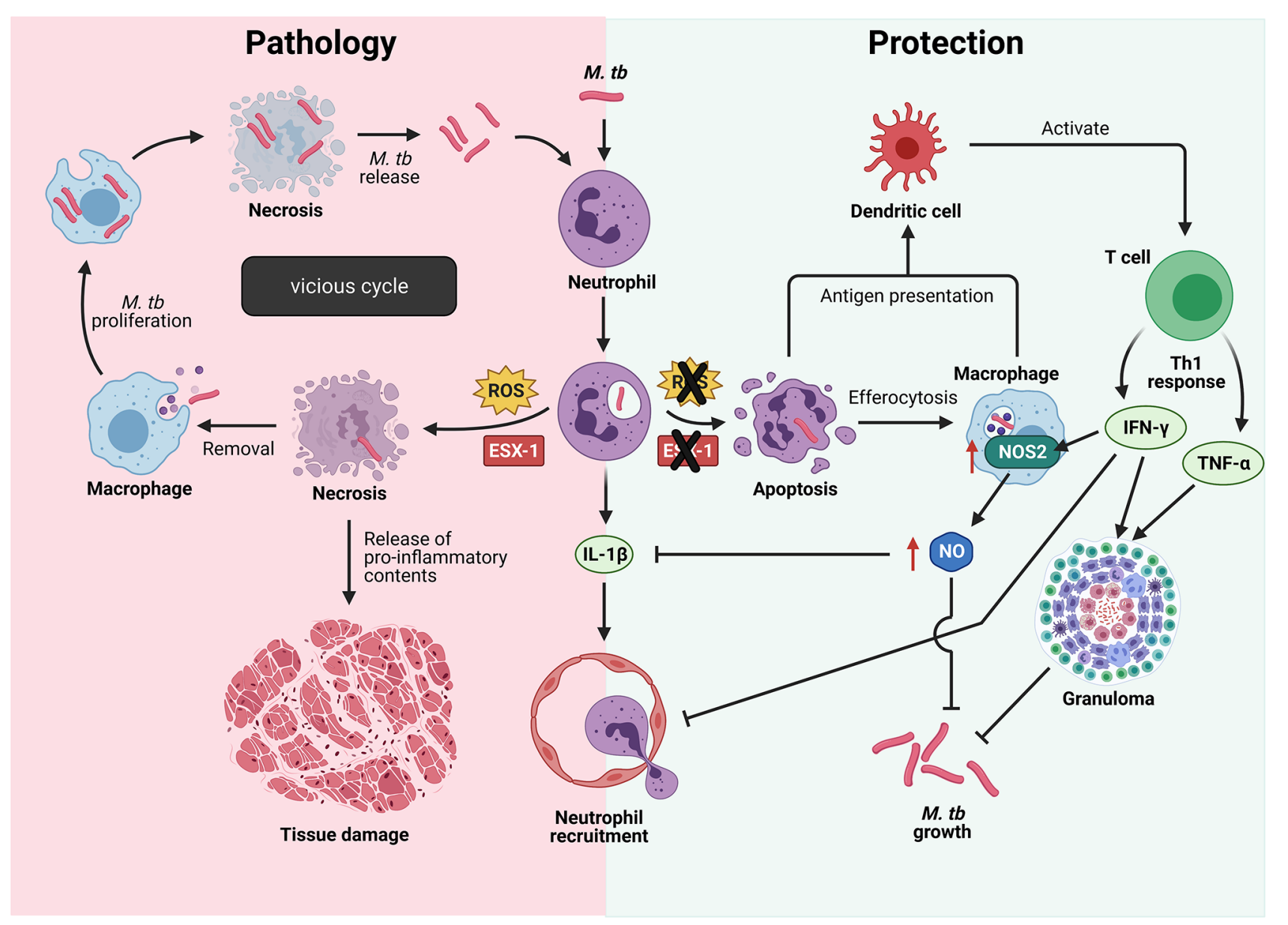

FIGURE 3 | Cell fate of $M$. tb-infected neutrophils determine protection or pathology in TB. Left: Virulent $M$. tb induces neutrophil necrosis in a reactive oxygen species (ROS)- and ESAT-6 secretion system 1 (ESX-1)-dependent manner, resulting in the release of bioactive molecules that damage surrounding host tissue. Removal of necrotic neutrophils by macrophages drive them into necrosis with subsequent release of virulent $M$. th to infect more host cells, thus resulting in a vicious cycle. Right: When the M.tb lacks a functional ESX-1 type 7 secretion system, or the production of ROS by neutrophils is inhibited, neutrophils undergo the default apoptosis instead. Cross-presentation of mycobacterial antigens to dendritic cells result in naïve T cell activation and differentiation into protective Th1 cells that produce interferon- $\gamma(\mathrm{IFN}-\gamma)$ and tumor necrosis factor- $\alpha$ (TNF- $\alpha$ ). IFN- $\gamma$-induced nitric oxide (NO) production limits inflammation by inhibiting neutrophil

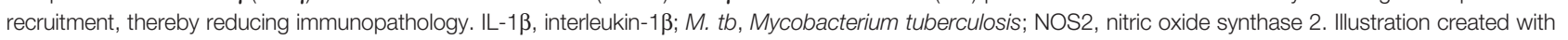
Biorender.com.

In contrast, when neutrophil ROS production is inhibited by pharmacological inhibition of myeloperoxidase (MPO), or when the ESX-1 secretion system is not functional in the attenuated $M$. $t b$ strain, neutrophils undergo apoptosis instead (99). Removal of apoptotic cells, also known as efferocytosis, contributes to host defense in TB. A study has shown efferocytosis of apoptotic neutrophils by macrophages to restore growth control of $M$. $t b$, as the attenuated $M$. $t b$ ended up in double- or triple-membrane compartment that they could not escape from without a functional ESX-1 secretion system (99). Moreover, efferocytosis of $M$. $t b$-induced apoptotic neutrophils markedly increased the production of TNF- $\alpha$ by human macrophages $(102,103)$ and resulted in a decreased viability of intracellular $M$. $t b$ (104). In addition, neutrophils promote the onset of adaptive immunity by delivering $M$. $t b$ to dendritic cells (DCs) in a manner that makes
DCs more effective in naïve CD4 T cell activation (86). Upon activation, naïve $\mathrm{T}$ cells differentiate into protective Th1 cells that secrete IFN- $\gamma$ and TNF- $\alpha$, two cytokines important in the maintenance of granuloma architecture to contain $M$. $t b$ (105109). Protective immunity during TB requires the host to restrict bacterial growth while limiting inflammation to prevent host tissue damage, and IFN- $\gamma$ is a key cytokine that serves both functions (110). IFN- $\gamma$ activates macrophages to kill intracellular mycobacteria and controls inflammation via direct and indirect inhibition of neutrophils (110-113). A study has shown IFN- $\gamma$ to directly inhibit neutrophil accumulation in $M$. $t b$-infected lung, thereby limiting lung inflammation (110). While IFN- $\gamma$-induced nitric oxide (NO) production by murine macrophages have direct anti-mycobacterial activity, $\mathrm{NO}$ also limits inflammation by inhibiting IL-1 $\beta$-dependent neutrophil recruitment (113). 
These studies highlight the complexity of host-pathogen interactions as well as the crucial role neutrophils play in determining host protection versus pathology in TB disease.

\section{Neutrophil Extracellular Traps}

Neutrophil extracellular traps (NETs) are a meshwork of chromatin fibres coated with cytoplasmic and granule-derived neutrophil antimicrobial peptides and proteases, and NETosis, as the name suggests, refers to the process of NETs release (114). While degranulation and phagocytosis are two long-established antimicrobial functions of neutrophils, NETosis as the third antimicrobial strategy was first described in 2004 (114). NETs allow neutrophils to eliminate pathogens more efficiently by immobilizing the pathogen to prevent its dissemination, and ensuring a high concentration of antimicrobial agents to degrade virulence factors and kill the pathogen (114). Ramos-Kichik et al. demonstrated that $M$. $t b$-infected neutrophils release NETs which trap mycobacteria but were unable to kill them, suggesting NETs prevent $M$. $t b$ from spreading to other organs while enhancing the local concentrations of released antimicrobial agents against $M . t b$ (115).

Since its discovery in 1996 (116), two types of NETosis have been characterized - late suicidal NETosis and early vital NETosis (Figure 4). Late suicidal NETosis, as the name suggests, occurs after several hours of stimulation and is dependent on NADPH oxidase (NOX) production of ROS, whereas early vital NETosis occurs within minutes of stimulation independent of oxidants (117). When NETosis is induced, protein arginine deiminase 4 (PAD4) is activated which converts arginine to citrulline in core histones, resulting in chromatin decondensation necessary for NET formation (118). In suicidal NETosis, NETs are expelled into the extracellular space upon plasma membrane disruption and the neutrophil dies (119), whereas in vital NETosis, NETs are released via nuclear envelope blebbing and vesicular export, and the plasma membrane remains intact (120-123). This explains why vital NETosis is mostly associated with bacterial infection, as it prevents the release of phagocytosed bacteria and the neutrophils stay alive to perform other immune functions, such as chemotaxis, phagocytosis, and killing of bacteria (124). NETs induction has been demonstrated in $M$. $t b$-infected neutrophils (115), but whether the neutrophils undergo vital or suicidal NETosis remains to be investigated. More recently, the finding of a novel form of NOX-independent NETosis that involves both apoptosis and NETosis in the same neutrophil, also known as apoNETosis (125), shows that much investigation remains to elucidate the mechanisms of NETs formation and to better understand the role of neutrophils in physiological and pathological processes.
A Late suicidal NETosis

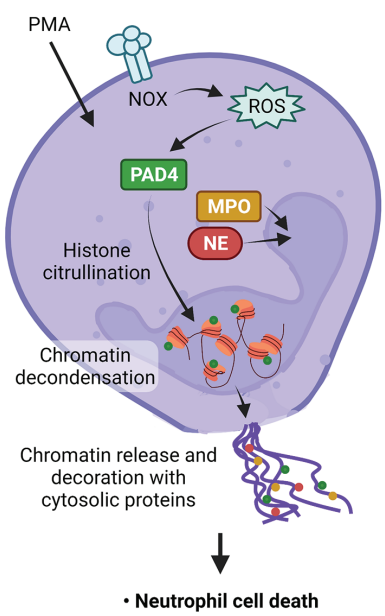

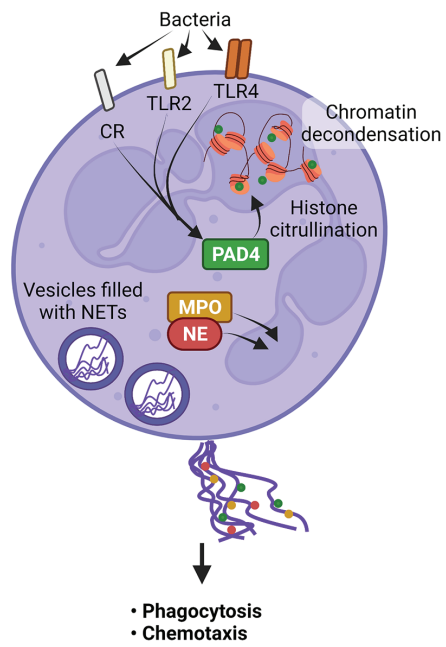

C ApoNETosis

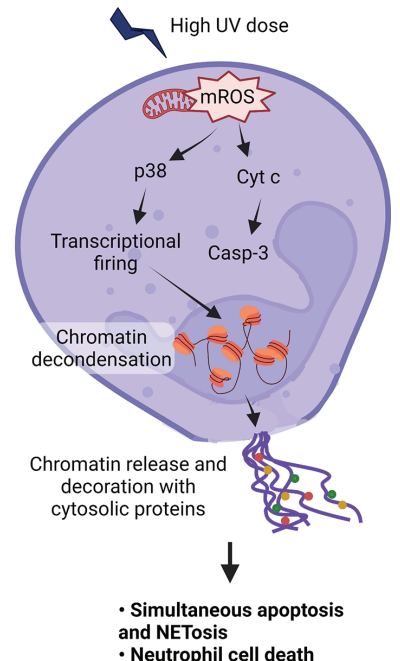

- O MPO Chromatin O CitH3 NETs

FIGURE 4 | Three types of NETosis induced by different stimuli. (A) Stimuli such as phorbol 12-myristate 13-acetate (PMA) induce suicidal NETosis after activating NADPH oxidase (NOX) to produce ROS. (B) Vital NETosis is induced within minutes by pathogens such as Staphylococcus aureus and Escherichia coli, through complement receptors (CR) and Toll-like receptors 2 and 4 (TLR2 and TLR4). This induces protein arginine deiminase 4 (PAD4) activation without the need for oxidants. Citrullination of histones allow chromatin to undergo decondensation and be dispersed in the form of NETs. NE and MPO translocate into the nucleus to promote further unfolding of chromatin. (C) ApoNETosis is induced by high-dose ultraviolet (UV) irradiation. This induces large amounts of mitochondrial ROS (mROS), caspase cascade activation, p38 activation, transcriptional firing and NETosis. Under apoNETosis conditions, although both apoptosis and NOXindependent NETosis occur simultaneously, NETotic events predominate apoptotic events. Unlike the other two types of NETosis, PAD4 is not activated and histones are not citrullinated. In addition, nuclear blebbing does not occur unlike classical apoptosis. Casp-3, caspase 3; CitH3, citrullinated H3; Cyt c, cytochrome c; MPO, myeloperoxidase; NE, neutrophil elastase; NETs, neutrophil extracellular traps; ROS, reactive oxygen species. Illustration created with Biorender.com. 
Transcriptional studies of human TB have been instrumental in unveiling the importance of neutrophils in TB disease (126), but the factors determining disease progression and the molecular mechanisms by which neutrophils drive TB pathogenesis remain poorly understood. A recent mechanistic study by Moreira-Teixeira et al. demonstrated that type I IFN exacerbated disease severity in TB-infected mice by inducing neutrophilic inflammation and NETs formation (127). The presence of NETs in necrotic lung lesions of patients with non-resolving pulmonary $\mathrm{TB}$ further supports the clinical relevance of NETs in TB pathogenesis (127). However, the description of NETs in TB is limited to pulmonary TB, and its role remains to be explored in CNS-TB.

Nonetheless, with increasing experimental and clinical evidence of NETs in TB pathogenesis, drugs that manipulate NETs structure or NETosis represent an attractive target for the development of therapeutics. DNase that digests NETs backbone is the oldest and one of the most attractive therapeutic interventions in NETs research (128), but a major limitation with this approach is that NETs-associated histones, proteases and other pro-inflammatory mediators become liberated upon DNA digestion, which can then cause local host tissue damage or systemic inflammation if this happens in the circulation $(129,130)$. Thus, NETs suppressive drugs that control NETs release without impacting the neutrophils' antimicrobial activities should be the focus of research moving forward. Screening of 126 compounds by the Palaniyar group to investigate their regulatory effects on NETosis has identified anthracyclines as a class of potent NETosis suppressive drugs (131). Notably, anthracyclines suppress both NOX-dependent and -independent NETs release by inhibiting chromatin decondensation and transcription, while maintaining the neutrophils' capacity to produce ROS that are crucial for their antimicrobial functions (131). In addition to this, Sollberger et al. also identified a molecule (LDC7559) that inhibits Gasdermin D, a pore-forming protein that punctures granules to release NE, and selectively suppress NETs formation without interfering with neutrophil phagocytosis (132). These selective pharmacological inhibitors of NETs formation present a promising avenue of research to be further explored.

M. $t b$-activated neutrophils also release heat shock protein 72 (Hsp72), a stress-induced protein that binds to NETs to trigger the secretion of pro-inflammatory cytokines TNF- $\alpha$ and IL- $1 \beta$ from adjacent macrophages (14). Apart from their proinflammatory and antimicrobial functions, NETs also provide a stimulus and scaffold for thrombus formation which leads to ischemic strokes and permanent brain damage, although the role of NETs in thrombosis have not been demonstrated in the context of TB $(7,15,16)$.

\section{Neutrophil Pathogenic Enzymes and ROS}

During $M$. $t b$ infection, neutrophils release NETs containing histones, MPO, MMPs and serine proteases such as neutrophil elastase (NE), proteinase 3 (PR3), and Cathepsin G (CtG) that may result in tissue damage $(114,115,118,133)$. Using a genetargeted approach, Guyot et al. demonstrated that neutrophil serine proteases (NSPs) CtG, PR3 and NE synergistically caused more tissue destruction than NE alone (133). Additionally, these
NSPs increased the activity of other tissue-destructive proteases such as macrophage elastase (MMP-12) and gelatinase B (MMP9) (133). MMPs, in particular MMP-9, play important roles in brain ECM degradation, resulting in BBB breakdown and brain tissue damage. In the analysis of human brain biopsy specimens, high concentration of neutrophils expressing MPO were present in the necrotic zone of the granuloma and within areas of brain infarction of TBM patients (47). The staining of NE and MMP-9 were also observed in CNS-TB human brain biopsies (9). Moreover, the whole-blood transcriptomic data of TBMimmune reconstitution inflammatory syndrome (IRIS) patients revealed an increase in neutrophil-dependent inflammatory response with significantly more neutrophil-associated transcripts including MPO, MMP-8 and -9 , CtG, lipocalin 2 (LCN2) and $\alpha$-defensin (DEFA1/3/4) compared to TBM nonIRIS (134). All these studies implicate neutrophils in driving immunopathology in CNS-TB.

M. $t b$-induced ROS production by neutrophil MPO has been shown to drive human neutrophils into necrotic cell death and directly damage the vascular endothelium and brain parenchyma $(100,135)$. ROS causes loss of endothelial barrier integrity by downregulating the expression of tight junction proteins, as well as inducing a shift in the membrane localization of tight junction proteins to the cytoplasm, thus increasing BBB permeability (136). A compromised BBB facilitates leukocyte transmigration into the CNS as well as influx of plasma resulting in edema. In addition, ROS disrupts the cadherin- $\beta$-catenin complex, which results in adherens junction disassembly at cell-cell contact, further contributing to BBB disruption (137).

\section{Neutrophil Cytokines and Chemokines in CNS-TB Immunopathology}

Activated neutrophils secrete a range of cytokines and chemokines to signal other innate and adaptive immune cells. For example, CCL-2, -3 and -20 recruit monocytes, CCL-17 recruits dendritic cells (DCs), and IL-6, TNF- $\alpha$ and IL-23 attract T lymphocytes to the site of infection (138). The concentration of CXCL-8, a predominant neutrophil stimulatory and chemotactic chemokine, was found to be increased in the CSF of TBM patients (139). Immunohistochemical staining showed that IL-2 and IL-17A, cytokines that enhance the recruitment of neutrophils and which have a role in pulmonary TB (140), were distributed intracellularly in the granulomas of TBM patients, contributing to a pathological inflammatory response (47). The finding of significantly increased CSF IL-17A concentrations in TBM-IRIS patients associated with severe CNS inflammation further supports a detrimental role for IL17A in CNS-TB (141).

Neutrophils produce TNF- $\alpha$, the key cytokine involved in the initiation of immune response to $M$. $t b$ and in the long-term control of infection. Not only is TNF- $\alpha$ important for macrophage activation and recruitment to the site of infection, TNF- $\alpha$ is also critical for granuloma formation and architecture to contain $M$. $t b$ (142). In keeping with the protective role of TNF- $\alpha$ against $M$. $t b$ infection, intracerebral $M$. $t b$-infected $\mathrm{TNF}^{-/-}$mice demonstrated an increased infiltration of leukocytes into the brain $(79,143,144)$, which may be explained by the inability of $\mathrm{TNF}^{-/-}$mice to effectively control $M$. $t b$, thereby resulting in an uncontrolled recruitment of 
immune cells into the CNS. While TNF- $\alpha$ confers protective immunity against $M$. $t b$, it also causes immunopathology by increasing BBB permeability (73). In addition, TNF- $\alpha$ and IL-17 have demonstrated synergistic pro-coagulant and pro-thrombotic effects on vessels (145), potentially contributing to ischemia stroke. Given the potential protective and pathological roles of TNF- $\alpha$ in CNS-TB, a "Goldilocks phenomenon" may exist where a certain amount of TNF $\alpha$ is required for the human host but excess is deleterious.

\section{MATRIX METALLOPROTEINASES AND THEIR ROLE IN CNS-TB}

MMPs are zinc-containing enzymes that degrade extracellular matrix at a neutral $\mathrm{pH}$. The MMP family comprises 25 related but distinct proteases of which 24 are found in mammals. In addition to ECM degradation, they have key functions in wound healing, angiogenesis, inflammation and host defense (146). MMPs can be broadly classified into several sub-families on the basis of substrate specificity, namely gelatinases, collagenases, stromelysins, matrilysin, metalloelastase and the membrane-type metalloproteinases (Table 2). While the classical ECM substrates include collagen, elastin and fibronectin, recent work has identified a variety of non-matrix substrates including adhesion proteins $(157,158)$, receptors (159), cytokines and chemokines (160-163). There is considerable overlap in MMP substrates, especially among the ECM proteins (164). Although the shared substrate potential may appear as a form of biochemical redundancy, the selectivity of MMP catalysis is regulated by enzyme affinity and compartmentalization (146). Kinetic studies have demonstrated that specific MMPs degrade some substrates more efficiently than others do. For example, MMP-2 and -9 degrade gelatin more efficiently

TABLE 2 | Matrix metalloproteinases, substrates and their activating capacity.

\begin{tabular}{lcc}
\hline Enzyme Common name & $\begin{array}{c}\text { Proposed substrate } \\
\text { of }\end{array}$ \\
\hline
\end{tabular}

\section{Gelatinases}

MMP-2 Gelatinase A (72$\mathrm{kDa}$ gelatinase)

MMP-9 Gelatinase B (92kDa gelatinase)

\section{Collagenases}

MMP-1 Collagenase-1 (fibroblast collagenase)

MMP-8 Collagenase-2 (neutrophil collagenase)

MMP- Collagenase-3 13

Stromelysins

MMP-3 Stromelysin-1

MMP- Stromelysin-2

10

MMP- Stromelysin-3

11

Membrane-type (MT) MMPs

MMP- MT1-MMP

14

MMP- MT2-MMP

15

MMP- MT3-MMP

16

MMP- MT4-MMP

17

\section{Other MMPs}

MMP-7 Matrilysin

MMP- Metalloelastase

12 (macrophage elastase)
Gelatin, collagen I, IV, V, VII, X, XI, XIV, gelatin, aggrecan, versican, proteoglycan link protein, tenascin, fibronectin, laminin, MMP-9, laminin-5, fibrillin, elastin, vitronectin, $\alpha_{2}-\mathrm{M}$, latent TNF, MBP, $\alpha_{1}-\mathrm{AT}$, neurocan, IL-1 $\beta$ precursor, CXCL-12, CCL-7, occludin, $\quad-13$ claudin-5

Gelatin, collagen IV, V, VII, X, XIV, aggrecan, versican, proteoglycan link protein, fibronectin, nidogen, elastin, vitronectin, $\alpha_{2}-\mathrm{M}$, latent TNF, latent TGF- $\beta$, latent VEGF, fibrin, NG2 proteoglycan, MBP, $\alpha_{1}-A T$, IL-1 $\beta$ precursor, occludin, claudin-5, $\mathrm{ZO}-1$

Collagen I, II, III (IIII)I), VII, VIII, X, gelatin, aggrecan, versican, proteoglycan link protein, L-selectin, nidogen, tenascin, serpins, MMP-2, $\alpha_{2}-\mathrm{M}$, latent TNF, MBP, $\alpha_{1}-\mathrm{AT}$

Collagen I, II, III (I>III), V, VII, VIII, X, gelatin, aggrecan, fibronectin, serpins, $\alpha_{2}-\mathrm{M}, \alpha_{1}-\mathrm{AT}$

Collagen I, II, III (II>I or III), IV, IX, X, XIV, gelatin, aggrecan, perlecan, fibronectin, laminin, tenascin, fibrillin, serpins

Collagen III, IV, V, IX, X, gelatin, versican, aggrecan, proteoglycan link protein, perlecan, fibronectin, laminin, tenascin, elastin, fibrillin, latent TNF, latent TGF- $\beta, \mathrm{MBP}, \alpha_{1}$-AT, antithrombin-III, IL-1 $\beta$ precursor, occludin, claudin-5, VE cadherin Collagen III, IV, V, gelatin, nidogen, aggrecan, proteoglycan link protein, fibronectin, elastin

$-8,-9,-13$ MMP-1, $-7,-8,-9$ $\alpha_{1}$-AT, fibronectin, laminin ND

Collagen I, II, III, gelatin, aggrecan, fibronectin, laminin, tenascin, vitronectin, fibrillin MMP-2, $-13$ Aggrecan, fibronectin, laminin, fibrin Gelatin, casein, fibrin, syndecan-1 MMP-2, $-13$ MMP-2

Gelatin, latent TNF

MMP-2

Collagen IV, X, gelatin, aggrecan, proteoglycan link protein, fibronectin, laminin, nidogen, vitronectin, pro- $\alpha$ defensins, FAS ligand, latent TNF, syndecan-1, E-cadherin, elastin, MBP, $\alpha_{1}$-AT

MMP-2, Collagen IV, gelatin, aggrecan, fibronectin, laminin, fibrillin, elastin, vitronectin, latent TNF, MBP, $\alpha_{1}$-AT

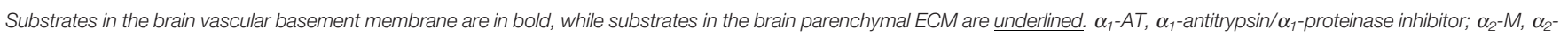

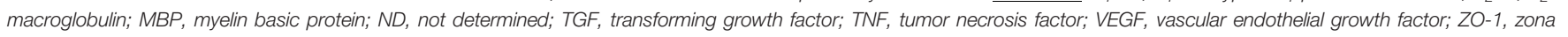
occludens 1. Adapted from (146-156). 
than other MMPs (165). Compartmentalization, which is the pericellular accumulation of MMPs, allow MMPs to target specific substrates in the pericellular space for catalysis (146). Cells do not indiscriminately release MMPs as that would result in non-specific proteolysis and tissue injury. Several reports have demonstrated specific interactions between MMPs and cell membrane anchors such as MMP-2 binding to $\alpha_{v} \beta_{3}$-integrin (166), MMP-9 to CD44 (159) and MMP-7 to surface proteoglycans $(167,168)$. This enables MMPs to accumulate to high concentrations locally and thus increase substrate specificity and catalysis efficiency.

The catalytic activity of MMPs are regulated by pro-enzyme activation and endogenous inhibitors such as $\alpha_{2}$-macroglobulin in the plasma and tissue inhibitors of metalloproteinases (TIMPs) in the tissue (169). While there are 24 mammalian MMPs, only four TIMPs (TIMP-1 - 4) have been identified that inhibit MMP activity by binding to their catalytic site in a $1: 1$ molar stoichiometry $(170,171)$. Similar to MMPs having variable substrate affinities, TIMPs also differ in their affinities for specific MMPs. Deciphering the activity of MMPs is made more challenging by the fact that MMP-TIMP interaction does not always lead to inhibition, as exemplified by the need for TIMP-2 to bind MMP-2 in a complex with membrane-bound MMP-14 to induce MMP-2 activation (146).

Excessive MMPs degrade the brain ECM, leading to BBB breakdown, plasma leakage and brain tissue destruction in CNSTB (Figure 5). The major MMPs that disrupt the BBB basement membrane are gelatinases MMP-2 and -9 , due to their ability to degrade type IV collagen, the main extracellular matrix of the $\mathrm{BBB}$. Under normal brain physiological conditions, MMP-2 is constitutively expressed in large amounts and can be found in the CSF (172). Conversely, MMP-9 is normally absent or present at low levels in the normal brain, and is upregulated during inflammation (173) or infection $(174,175)$. Neutrophils may be the main cellular source of MMP-8/9 $(7,9)$. Our work demonstrated that MMP-9-expressing neutrophils were present in tuberculous granulomas in CNS-TB and neutrophil-derived MMP-9 secretion was upregulated by $M . t b$ (9). Apart from type IV collagen, the gelatinases are also capable of degrading laminin, fibronectin, nidogen, versican, aggrecan, tenascin and proteoglycan link protein found within the cerebral vascular basement membrane and parenchymal ECM (147). Additionally, MMP-2 and -9 have been demonstrated to degrade TJPs occludin and claudin-5, thereby further increasing BBB permeability (148). Thus, gelatinases MMP-2 and -9 likely play key roles in mediating $\mathrm{BBB}$ breakdown and tissue destruction in the brain. A compromised BBB results in plasma leakage into the CNS, causing vasogenic edema and further facilitates the influx of circulatory inflammatory cells into the brain.

In organs like the brain, interactions between different cellular networks influence the eventual MMP expression, which in turn define the final pathophysiological consequence. We have previously demonstrated that astrocytes and microglia secrete MMP-9, -1 and -3 respectively in response to $M$. $t b$-infected monocytes but not upon direct $M$. $t b$ infection $(176,177)$. This network-dependent secretion of MMPs is driven by pro- inflammatory mediators TNF- $\alpha$ and IL-1 $\beta$. In addition to its role as an activator of MMP-9, a recent study has shown the importance of MMP-3 in BBB breakdown by reducing tight junction and VE-cadherin proteins in brain microvascular endothelial cells (149). LPS-activated microglia have significantly reduced TNF- $\alpha$ in the presence of a broad spectrum MMP inhibitor BB94 (178), while a separate study similarly reported that inhibition of MMP-3 or -9 resulted in a suppression of iNOS, IL-1 $\beta$, IL-1Ra and IL- 6 gene expression, and TNF- $\alpha$ at the post-transcriptional level in activated microglia (179). Thus, MMPs may influence cytokine secretion in microglia, suggesting a potential effect of neutrophil-derived MMPs in mediating microglia's cytokine responses during CNS-TB.

Although many studies have focused on the contribution of MMPs to host immunopathology, there is increasing evidence to show that these proteases also play a crucial role in granuloma formation (180). Several MMPs have been shown to cleave and modulate the functions of cytokines and chemokines such as IFN- $\gamma$, IL- $1 \beta$, TNF- $\alpha$, CXCL- 8 and CCL-7, thereby regulating chemokine gradients and leukocyte recruitment to the site of infection (146). Treatment of pulmonary TB mouse models with batimastat, a broad-spectrum MMP inhibitor, resulted in a delayed induction of granuloma or the formation of smaller granulomas with increased collagen content $(181,182)$, but the same has not been shown for CNS-TB. Consistent with these findings, MMP-9-deficient mice demonstrated a reduced recruitment of macrophages leading to the development of smaller granulomas (183). Thus, while MMPs are believed to degrade ECM substrates as their primary function, some MMPs, such as MMP-9, may also have dual roles in tissue remodeling and ECM deposition (180).

\section{MMP Studies in Human CNS-TB and the Gaps in Knowledge}

Research into BBB disruption in human CNS-TB is limited, but several studies have lent evidence on the pathogenic role of MMPs in CNS-TB (10, 184-187), and that MMPs may drive BBB breakdown and CNS-TB immunopathology. Specific MMPs and TIMPs in the CSF and systemic circulation of TBM patients may provide an indication of the overall MMP activity in vivo (184, 186) and may be a surrogate of BBB breakdown. However, the current gap is the lack of direct association of MMP concentrations and an accepted index of BBB breakdown (10, 188, 189).

Numerous studies have found CSF MMP-9 concentrations in TBM patients to be upregulated, with MMP-9 upregulation associated with disease severity (190), neurological complications $(184,186)$, and brain tissue damage $(185,186)$. Another member of the gelatinase sub-family MMP-2 was also implicated in TBM pathogenesis. Patients with subacute meningitis, including fungal meningitis and TBM, had higher CSF MMP-2 and -9 as well as TIMP-1 (but not TIMP-2) than patients with non-inflammatory neurological diseases. Increased MMP-9 correlated with CNS complications including depressed consciousness and psychiatric symptoms (185). Furthermore, 


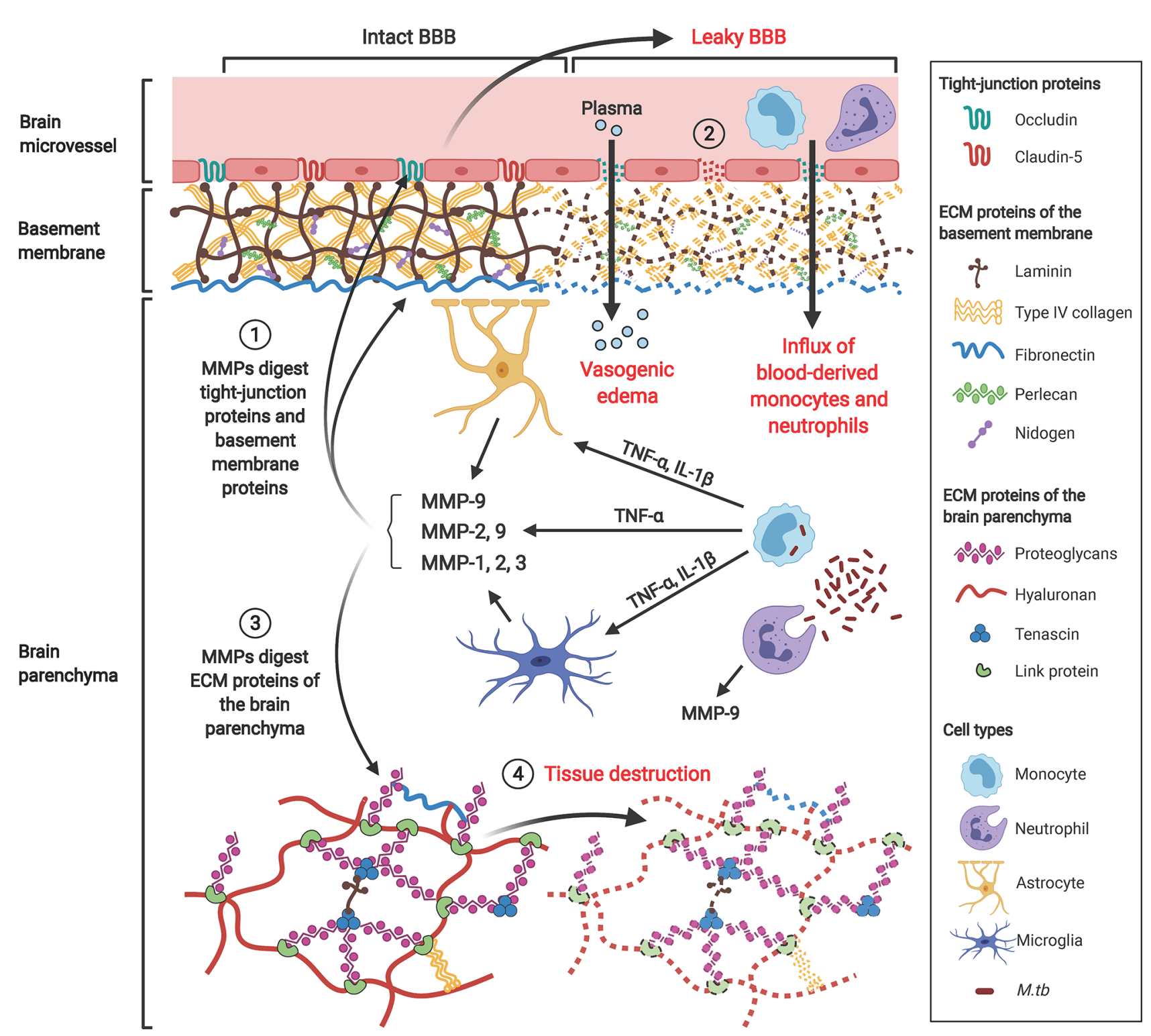

FIGURE 5 | Gelatinases MMP-2 and -9, collagenase MMP-1 and stromelysin MMP-3 contribute to BBB breakdown and brain tissue damage in CNS-TB. M. tbinfected monocytes interact with astrocytes and microglia in the brain to induce their secretion of MMP-9, -1 and -3 respectively, a process that is driven by proinflammatory mediators TNF- $\alpha$ and IL-1 $\beta$. (1) These MMPs degrade TJPs occludin and claudin- 5 and ECM proteins of the basement membrane including type IV collagen, laminin, nidogen, perlecan and fibronectin. (2) This BBB breakdown drives influx of plasma resulting in vasogenic edema and facilitates further influx of circulating inflammatory cells such as monocytes and neutrophils into the brain. (3) MMPs also degrade proteoglycans (aggrecan, versican, brevican), proteoglycan link proteins and tenascins found within the ECM of the brain parenchyma, thus resulting in (4) brain tissue destruction adding to the cerebral inflammatory response. MMP-9 secreted from neutrophils further compromise the BBB and exacerbate tissue damage. Illustration created with Biorender.com.

the upregulated MMP-2 and -9 concentrations in CSF persisted late into the course of TBM (187), indicating that antituberculous treatment (ATT) is ineffective in reducing gelatinase MMP-2 and -9 concentrations. The inability of standard ATT to mitigate the increased MMP-2 and -9 concentrations in TBM patients indicates that there is an urgent need to explore adjunctive treatment to suppress these pathogenic MMPs. A study conducted by Green et al. found that adjunctive dexamethasone, the standard of care in CNS-TB, significantly decreased CSF MMP-9 concentrations in TBM patients, but the decline in MMP-9 concentrations was not associated with improved outcome (10). The concentration of MMPs should be considered in relation to their specific endogenous TIMPs, as the balance between MMP and TIMP concentrations determine the overall MMP activity, thereby influencing TBM pathogenesis and patient outcome. 20 years ago, our group showed for the first time a significant increase in MMP-9 but not TIMP-1 in the CSF of TBM patients, suggesting 
a matrix-degrading phenotype in TBM where MMP-9 activity was relatively unopposed by TIMP-1 (186). In addition, the imbalance of MMP-9:TIMP-1 ratio correlated with mortality and neurological morbidity (such as unconsciousness, confusion and neurological deficits) in TBM patients (186).

However, the association between increased MMP-2 and -9 concentrations and poor patient outcome is not consistent, and several studies have demonstrated no association between MMP concentrations and outcome $(188,189,191,192)$. This is unsurprising as MMPs, specifically MMP-2, -3, and -9, also play important roles in normal brain development. There is increasing evidence that MMPs perform diverse functions, both protective and pathological, at different concentrations, in different age groups and at different time points of infection (193), which may explain these differing observations. In a recent study of 40 TBM patients by Mailankody et al., CSF-serum albumin index was used as an indicator of BBB permeability, but there was no association between CSF MMP-9 and the CSFserum albumin index. Both MMP-9 and TIMP-1 were also not associated with treatment outcome. In contrast, a significant positive correlation between MMP-9 levels and Glasgow coma scale (GCS) was found, indicating that higher MMP-9 concentrations were associated with a favourable outcome (188). In a study of pediatric TBM infections, higher MMP-9 concentrations were found to be associated with a good outcome, possibly due to the role of MMP-9 in recovery and ongoing neurodevelopment, including angio- and myelino-genesis, synaptic plasticity and the growth of axons (189). Thus, there is conflicting literature on whether MMP-9 is protective or pathogenic which is likely to reflect diverse patient populations.

TB granulomas (tuberculomas), which occur frequently in CNS-TB, demonstrate high expression of several MMPs including MMP-1, -2, -3 and -9 (Figure 6) (9, 176, 184, 185). Immunohistochemical analysis of brain biopsies from CNS-TB patients demonstrated that MMP-2 and -9 exhibit distinct localization within the brain granuloma (185). While infiltrating mononuclear cells in the meninges demonstrated immunoreactivity for both MMP-2 and -9 , mononuclear cells

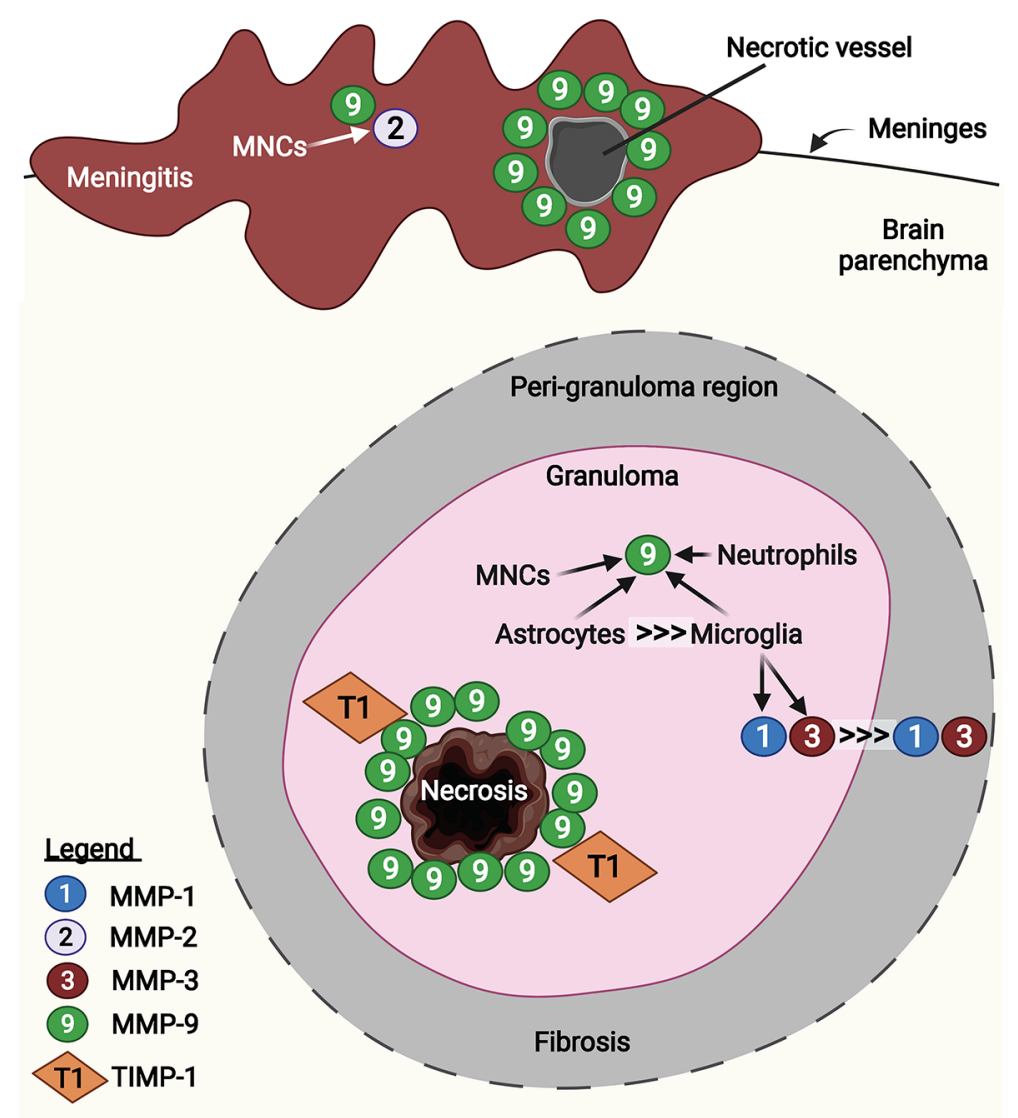

FIGURE 6 | MMP-1, -2, -3, and -9 are expressed in human CNS-TB granulomas. Infiltrated mononuclear cells (MNCs) in the meninges were immunoreactive for MMP-2 and -9. In particular, MMP-9 was expressed in the perivascular leukocytes at necrotic vessel, contributing to BBB disruption (185). In the granuloma, MMP-9 was highly expressed around the area of caseous necrosis, unopposed by TIMP-1 (194). Astrocytes are the main CNS cellular source of MMP-9, compared with other sources including MNCs, neutrophils and microglia (184). Microglia-derived MMP-1 and -3 were found decreasing towards fibrosis peri-granuloma region (176). Illustration created with Biorender.com. 
that infiltrated into the brain parenchyma were immunoreactive for MMP-9 but not MMP-2 (185). In meningeal vessels that showed necrotic changes, MMP-9 was expressed in the perivascular leukocytes, thereby providing evidence that MMP9 is associated with BBB disruption in TBM in vivo (185). The role of MMP-9 in brain tissue damage was corroborated by the high MMP-9 expression around the area of caseous necrosis in TB granuloma, which was relatively unopposed by the presence of few TIMP-1-positive stromal cells (194). Harris et al. also demonstrated upregulated MMP-9 secretion in astrocytes near CNS-TB granulomas and downregulated TIMP-1 expression in the brain tissue of CNS-TB patients (184). Additionally, although both astrocytes and tissue-resident macrophages and microglia expressed high MMP-9 in the CNS-TB brain tissue, macrophages and microglia were present as much lower numbers than the astrocytes, indicating astrocytes as the major CNS cellular source of MMP-9 in CNS-TB (184). By immunostaining for MMP-9 and neutrophil elastase, we demonstrated the presence of MMP-9 secreting neutrophils in CNS-TB granulomas (9). In addition to MMP-9, MMP-1 and -3 secretion were also found to be highly expressed in the center of granuloma which decrease towards the fibrotic, peri-granuloma region (176). This increased expression of MMP- 1 and -3 were associated with microglia in the granuloma and peri-granuloma region and p38-positive microglia infiltrating necrotizing CNS-TB granulomas $(176,195)$. Collectively, these results support a role for MMPs, in particular MMP-1, -3, and -9, in brain tissue destruction in CNS-TB patients. However, the contribution of MMP-2 to BBB breakdown and tissue damage in CNS-TB remains further evaluation, as TNF $\alpha$ has been shown to suppress microglial MMP-2 secretion by $M$. $t b$-infected monocytedependent networks (195).

Stromelysin MMP-10 is functionally important in TB. It was found upregulated in induced sputum and bronchoalveolar lavage fluid from TB patients compared to respiratory symptomatic controls (196). The inhibition of MMP-10 activity has shown to decrease DQ collagen degradation by $M$. $t b$-infected macrophages, and its upregulation in macrophages was induced by virulent $M$. $t b$ in Early Secretory Antigenic Target-6 (ESAT-6)-dependent manner (196). Rohlwink et al. proposed that MMP-10 and IL-17augmented MMP-3 (140) may activate MMP-1 to propagate collagenase activity in cellular networks (193). M. $t b$ stimulation of peripheral blood mononuclear cells (PBMCs) from TB-IRIS patients also found with elevated MMP-1, $-3,-7$, and -10 protein secretion compared to non-IRIS controls (197). Similarly, the concentrations of CSF MMP-1, -7 , and -10 , together with neutrophil-associated mediators were found higher in TBM-IRIS than non-IRIS controls (141). However, the functional role of MMP-10 in CNS-TB, and whether it is associated with MMP-3 and neutrophils and their mediators remains an open question.

\section{NEUTROPHILS AND STROKES IN CNS-TB}

Ischemic stroke is a devastating complication found in 15- 67\% of TBM patients, associated with poor outcome and higher mortality compared to those without stroke $(198,199)$.
A higher incidence of stroke was reported in younger children and those with advanced stages of TBM (200). CSF white cell count and basal meningeal enhancement were identified as independent risk factors for stroke in young TBM patients (201). Most of the strokes in TBM are multiple, bilateral and located in the basal ganglia $(198,199)$. The extensive damage of cerebral vessels or vasculitis contributed to widespread infarctions in TBM patients (202), which was significantly associated with hydrocephalus (203). Dysregulated inflammation is likely to contribute to TBM-related stroke. The upregulated inflammatory cytokines TNF- $\alpha$, MIP-1 $\alpha$, IL6 , IL-8, IL-4 and IL-1 $\beta$ concentrations in CSF samples were correlated with the presence of infarcts in TBM patients (204, 205). In another study, the concentrations of lipocalin-2, soluble receptor for advanced glycation end products (sRAGE) and CXCL10 were significantly higher in the CSF of children with TBM-related stroke compared to TBM without stroke (206). Moreover, Schoeman et al. reported a prothrombotic profile of TBM children, with increased procoagulant factor (Factor VIII) expression and decreased in both anticoagulant Protein $\mathrm{S}$ expression and fibrinolytic activity (207). These findings also indicated a hypercoagulable state in TBM which is more pronounced in stage III of TBM with increased risk of thrombosis and infarction (207). Platelets are likely to be key in the inflammatory and thrombotic response to CNS-TB (60).

Since its first description in 2004, NETs have been implicated in many non-infectious diseases associated with thrombosis, including diabetes mellitus, autoimmune diseases, atherosclerosis, vasculitis, and thrombosis (117). In vivo, NETs are degraded by plasma deoxyribonucleases (DNases) to facilitate their subsequent clearance by macrophages (208-210). Mice deficient in DNase-1 and -3 die within several days after neutrophil activation due to blood vessel occlusion by intravascular NETs, suggesting a role for NETs in clot formation (208). The presence of citrullinated histone 3 (CitH3), a NETosis marker, in the thrombi of mice and humans; and the finding that mice form smaller thrombi when treated with DNase, further support this hypothesis (211-214). The clinical importance of NETs in thrombosis is highlighted in the study by Ducroux et al., where they demonstrated, through histological analysis, that NETs structures were concentrated in the outer layers of patient-derived ischemic stroke thrombi, and that ex vivo thrombolysis was accelerated when DNase-1 was added to the standard tissue plasminogen activator (16). Another study that analysed 86 thrombi from ischemic stroke patients undergoing endovascular treatment supported this finding (215). The mechanisms by which NETs stimulate thrombus formation and NETs-induced coagulation remains to be fully dissected.

There may be synergistic interaction between NETs generated in response to $\mathrm{TB}$ infection and platelets in thrombosis (Figure 7) (216). While NETs promote thrombin generation (217), activated platelets, in turn, trigger NETs formation (218). During thrombosis, hypoxia-induced release of von Willebrand factor (vWF) and p-selectin from the endothelium recruits and activates neutrophils, initiating NETs production $(219,220)$. Platelets interact with $\mathrm{C} 3 \mathrm{~b}$ and histones on NETs to stimulate the secretion of polyP, a compound that activates the extrinsic 


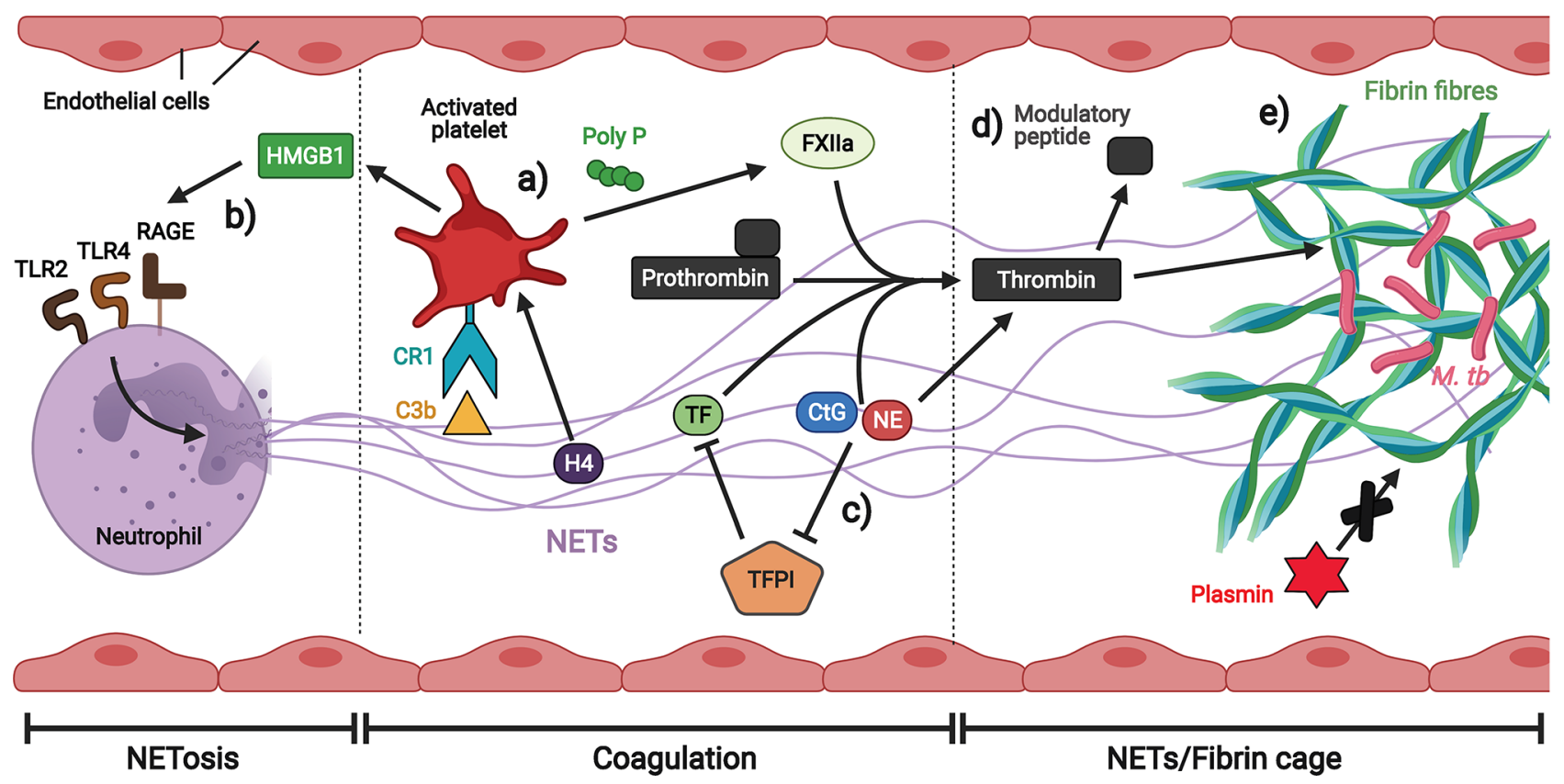

FIGURE 7 | Neutrophil extracellular traps (NETs) promote thrombosis in brain microvessels. (A) Platelets interact with C3b and histones on NETs to stimulate the secretion of polyP which activates the extrinsic coagulation pathway. (B) Platelet-derived HMGB1 induces NETosis. (C) Multiple components of NETs induce coagulation either directly or by inhibiting the extrinsic coagulation pathway inhibitor. (D) NE is able to generate thrombin-derived immune modulatory peptides.

(E) Fibrin fibres strengthened by NETs immobilize M. th and are less prone to degradation by plasmin. Illustration created with Biorender.com.

coagulation pathway by activating factor XII (FXIIa) (221-224). In addition, histone 4 (H4) on NETs activates platelets to secrete high mobility group box 1 protein (HMGB1), a damage associated molecular pattern (DAMP) that stimulates NETosis by RAGE (Receptor for Advanced Glycation End products), TLR2 and TLR4 receptors, thereby creating a positive feedback loop (212). In general, NETs associated with platelets serve as a scaffold on which thrombi can form, and several components of NETs have been shown to induce fibrin generation. Tissue factor (TF) induces thrombin cleavage directly (225), while the negatively charged nucleic acids bind and activate FXII (213). NETs-associated serine proteases $\mathrm{NE}$ and $\mathrm{CtG}$ also contribute to fibrin formation on NETs by degrading tissue factor pathway inhibitor (TFPI), the main extrinsic coagulation pathway inhibitor (226). CtG has also been demonstrated to proteolytically activate platelet receptors to enhance platelet accumulation (227). In addition, NE cleaves prothrombin to generate small antibacterial peptides that exert immunomodulatory effects, thereby providing a logical rationale for the induction of coagulation by NETs: the generation of antibacterial molecules as a by-product of coagulation for host defense (15). The fibrin clots can also serve an antimicrobial function by strengthening NETs structure to immobilize pathogens and limit their spread.

Correlative light and electron microscopy (CLEM) images of NETs and fibrin fibrils in lung tissue sections of legionnaire's pneumonia provide evidence that both structures are interwoven (228-230). However, interwoven NETs/fibrin structures form a scaffold that entraps platelets and red blood cells (RBCs) $(213,231)$ and are more resistant to plasmin-mediated fibrinolysis, which may contribute to pathology in several thrombosis-related diseases (232), including strokes in CNS-TB, although this has not been proven. Further investigation on the interaction between NETs and platelets in the context of CNS-TB to uncover their potential immunopathology mechanisms are warranted.

\section{ADJUNCTIVE THERAPY FOR CNS-TB}

The recommended anti-tuberculous treatment regime for CNS-TB was largely extrapolated from the principles of treatment for pulmonary TB, as no clinical trial has managed to establish the optimal therapy for CNS-TB (39). While the drug composition and dosing of treatment regime is the same as for pulmonary TB, treatment duration for CNS-TB is extended to 10 to 12 months (233). The first 2 months of intensive phase of treatment uses a 4drug combination of rifampin (RIF), isoniazid (INH), pyrazinamide (PZA), and ethambutol (EMB), followed by a 2drug combination of RIF and INH in the continuation phase (234). With respect to the efficacy of ATT drugs in crossing the bloodbrain barrier (BBB), INH and PZA showed excellent CSF penetration, while RIF and ETH have limited CSF penetration $(233,235)$. Although CSF concentration of RIF is only $10 \%$ of plasma, which barely exceeds the minimum inhibitory concentration (MIC) against $M . t b$, the high mortality associated with RIF-resistant TBM affirms its key role in CNS-TB treatment (236). 
Several clinical trials have evaluated the efficacy of a highdose RIF as an intensified ATT regime for TBM, but have met with contradicting results (237-239). The use of high-dose intravenous (i.v.) RIF (13mg/kg) for the first 2 weeks significantly reduced mortality at 6 month by about $50 \%$ (237). In contrast, there was no association between highdose RIF treatment $(15 \mathrm{mg} / \mathrm{kg})$ and improved survival at 9 months (238). Another study which increased the RIF dosage to $30 \mathrm{mg} / \mathrm{kg}$ found no significant difference in 6-month mortality between the $10-, 20-$ and $30 \mathrm{mg} / \mathrm{kg}$ oral RIF treatment arms (239).

Nonetheless, clinical outcome of CNS-TB patients are often poor even with ATT. Long-term neurological deficits occur in 5 to $40 \%$ of surviving TBM patients, and studies that performed repeated MRI/CT scans in TBM patients on ATT reported frequent worsening of radiological findings $(66,240-243)$. This signifies a need to develop new interventions to improve outcome, which led to an increased research interest in repurposing existing drugs as adjunctive therapies.
As the infection progresses, TB granulomas evolve from a solid, non-necrotic structure that is capable of controlling $M$. $t b$ growth to a necrotic phenotype that leads to host tissue damage and bacterial persistence (244). Host-directed therapies (HDTs) are adjunctive treatment with ATT to mitigate the TB immunopathology by reducing inflammation and reprogramming granuloma structure (244). Treatment that ameliorate the neutrophil-driven inflammatory responses should be considered. To date, the three major HDTs being investigated for CNS-TB management are steroids, aspirin and anti-TNF- $\alpha$ agents (Figure 8). Clinical features of TBM such as seizure and raised intracranial pressure may require drugs such as anti-epileptics, diuretics acetazolamide and furosemide (249).

\section{MMP Inhibition as Potential Developments in the Field of Therapeutics}

Given the pivotal role of MMPs in BBB breakdown and CNS tissue destruction in CNS-TB, there is increasing evidence that targeting MMPs or their upstream regulatory pathways may

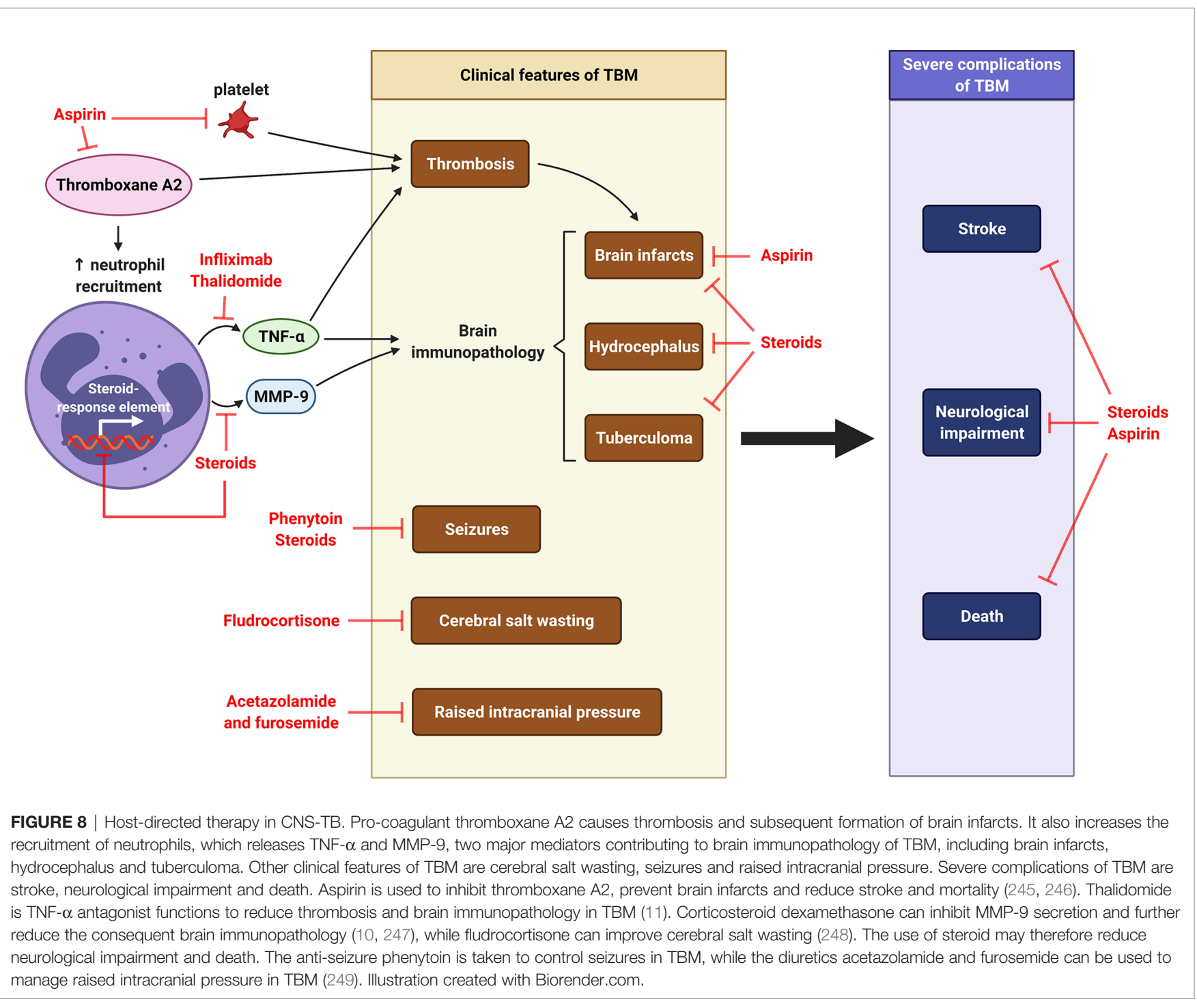


improve treatment outcomes (250). Glucocorticoids such as dexamethasone are established adjunctive therapies for CNS$\mathrm{TB}$, and adjunct dexamethasone reduces mortality of TBM patients by $30 \%$ (62). However, the mechanism for this effect is not understood. In vitro CNS-TB studies have demonstrated dexamethasone suppressed mRNA expression and secretion of MMP-1 and -3, but not TIMP-1 and -2 (176). This suggests that dexamethasone may tip the protease: anti-protease balance in favor of reduced overall proteolytic activity, thereby reversing the matrix degrading phenotype in CNS-TB, and may be the mechanism by which corticosteroids improve outcome in TBM patients. The specific mode of action of dexamethasone on MMP expression is corroborated by a clinical study where adjunctive dexamethasone significantly reduced CSF MMP-9 concentrations in TBM patients, but had no effect on other MMPs, TIMPs, cytokines or chemokines $(10,247)$. In addition, CSF MMP-9 concentrations showed a strong correlation with CSF neutrophil count, indicating a central role of neutrophils in TBM pathogenesis (10). However, in vitro CNS-TB studies found anti-TNF- $\alpha$ treatment, but not dexamethasone, suppressed neutrophil MMP-9 secretion (9). The authors postulated that other MMP-9-secreting CNS cells such as astrocytes, microglia and neurons may contribute to the total suppression of CSF MMP-9 observed in the adjunctive dexamethasone-treated TBM patients.

Although MMP secretion may be affected by medications, drugs that specifically target MMPs, in particular MMP-9, would minimize off-target effects such as immunosuppression as in the use of steroids. To date, there is only one study that investigated the effect of specific MMP inhibition in an animal model of CNS-TB. Adjunctive SB-3CT, which is an inhibitor specific for MMP-2 and -9, appeared more effective than dexamethasone in $M$. $t b$ clearance and MMP-9 suppression in a murine CNS-TB model (251). Nonetheless, further studies are needed to determine the role of MMP inhibition in improving CNS-TB treatment outcomes.

\section{Steroids and Controversies on Its Use to Decrease Neurological Sequelae}

Corticosteroids, which include prednisolone, methylprednisolone and dexamethasone, are anti-inflammatory drugs commonly used to treat autoimmune diseases. They are known to decrease the secretion of inflammatory mediators from neutrophils. The use of corticosteroids as an adjunctive HDT for TBM is thought to reduce mortality by decreasing inflammation in the brain and its associated blood vessels, as well as reducing intracranial pressure (252). However, corticosteroids can suppress the host immune system, resulting in uncontrolled $M$. $t b$ growth and reduced meningeal inflammation, which then reduces the ability of therapeutic drugs to cross the BBB (252). Thus, the benefit of corticosteroids as an adjunct therapy for TBM remains controversial. A review of 1,337 participants across 9 clinical trials concluded that adjunctive corticosteroids improved the short-term survival of TBM patients by approximately $25 \%$, but were ineffective in mitigating against neurological disabilities (252). However, serial brain MRI conducted on dexamethasonetreated TBM patients suggested a reduced incidence rate of hydrocephalus and infarction (253). An immunological study that evaluated the effect of adjunctive dexamethasone on TBM treatment reported prolonged inflammatory responses in all TBM patients regardless of treatment group (247). Dexamethasone slightly decreased CSF IFN- $\gamma$ concentrations, but did not alter immunological and routine biochemical indices of inflammation or peripheral blood monocyte and $\mathrm{T}$ cell responses to $M$. $t b$ antigens (254). This indicates that the improved survival in dexamethasone-treated TBM patients was not due to an attenuation of inflammatory mediators in the CSF or a suppression of peripheral immune responses to $M$. $t b$ antigens (254). The mechanism of action of adjunctive corticosteroids in reducing mortality is uncertain but adjunctive dexamethasone significantly suppressed CSF MMP-9 concentrations, which may be neutrophil-derived, in TBM patients $(10,247)$.

However, the utility of adjunctive corticosteroids in reducing neurological complications associated with CNS-TB remains controversial. A recent study on patients with CNS tuberculomas reported that an intensified adjunctive dexamethasone therapy (for several months up to 18 months) led to an improvement of neurological symptoms such as seizures, stupor and disturbed vision and a complete resolution of CNS lesions (255). The authors demonstrated that when dexamethasone was tapered according to the guidelines for TBM, all patients exhibited neurological deterioration which immediately improved upon increasing the dexamethasone dose (255). This discrepancy may be attributed to the possibility that most CNS-TB studies and treatment regime do not discriminate between the different entities of CNS-TB such as TBM and intracranial tuberculomas (255). The effect of adjunctive corticosteroid treatment in CNS-TB had been evaluated only for TBM patients (252), but not for patients with intracranial tuberculomas without meningitis. This study, together with a few others, that showed worsening of symptoms coinciding with the reduction or termination of corticosteroids (256-258), strongly suggests that the duration and dosage of adjunctive corticosteroid therapy in CNS tuberculomas are different from the TBM regime. It also highlights the importance of future CNS-TB clinical studies to clearly distinguish between TBM and CNS tuberculomas so that they can be more effectively managed.

\section{Aspirin}

Even with effective ATT, up to $40 \%$ of surviving CNS-TB patients sustain neurological morbidities due to strokes (245). This led to the use of adjunctive aspirin for the prevention of ischemic strokes in TBM treatment $(245,246,259)$. In the first randomized controlled trial of 118 Indian adult TBM patients, aspirin was associated with a non-significant reduction in stroke at 3 months, and a significant reduction in mortality (246). The second randomized controlled trial compared low $(75 \mathrm{mg} / \mathrm{kg}$ ) and high $(100 \mathrm{mg} / \mathrm{kg})$-dose aspirin and placebo in 146 South African pediatric TBM patients (259). Although adjunctive aspirin (regardless of dosage) showed no effect on mortality and morbidity, the outcome in high-dose aspirin group compared favorably with other treatment groups despite a significantly younger age and more severe neurological comorbidity, which warrants further investigation of aspirin in 
TBM (259). While low-dose aspirin (75-150 mg) is sufficient to prevent ischemic cerebrovascular disease, higher-dose aspirin (>600 mg) is required for its anti-inflammatory effects $(260,261)$. In addition, aspirin's inhibitory effect on platelets and thrombus formation may explain its role in reducing stroke-related mortality (262). A trial which compared low (81 mg)- and high $(1000 \mathrm{mg})$-dose aspirin and placebo in 120 adult Vietnamese TBM patients found aspirin to inhibit in a dosedependent manner on pro-coagulant thromboxane A2 and upregulation of CSF protectins that promote resolution of inflammation (245). This finding supports aspirin in preventing TBM-related brain infarction by its anti-thrombotic, antiinflammatory, and pro-resolving properties, and a larger study is needed to confirm the beneficial role of aspirin in preventing strokes in TBM patients (245).

Aspirin treatment likely exert its therapeutic effects by resolving neutrophil-mediated inflammation. In murine experiments, aspirin-induced anti-inflammatory lipoxins production to inhibit neutrophil- and platelet-mediated lung inflammation (263) and decreased systemic neutrophilic recruitment in pulmonary TB (264). Aspirin has also been shown to reduce NETs formation in PMA-stimulated human neutrophils (265). In a human model of acute respiratory distress syndrome, aspirin reduced pulmonary neutrophilia and MMP-8, -9 (266). However, the effects of aspirin on the neutrophilderived MMP-8, -9 in CNS-TB have not been studied.

\section{Anti-TNF- $\alpha$ and Other Approaches to Host-Directed Therapies}

Adjunctive therapy with thalidomide, a TNF- $\alpha$ antagonist, has demonstrated an improvement in survival and neurological outcome in rabbits, but not in human CNS-TB (11). Not only do human studies failed to show a correlation between TNF- $\alpha$ levels and disease severity or outcome, a clinical trial of adjunctive thalidomide in paediatric TBM patients was prematurely terminated due to adverse events and a lack of benefit in the thalidomide arm (11).

In summary, existing trials on the use of steroids as adjunctive therapy for CNS-TB showed that they may be beneficial in improving the survival of CNS-TB patients by reducing CSF MMP-9 concentrations, thereby reducing brain immunopathology such as infarcts and hydrocephalus. Conversely, adjunct aspirin and

\section{REFERENCES}

1. Global Tuberculosis Report 2020. Geneva: World Health Organization. (2020). p. 232. Licence: CC BY-NC-SA 3.0 IGO

2. Cherian A, Thomas SV. Central Nervous System Tuberculosis. Afr Health Sci (2011) 11(1):116-27.

3. Garg RK. Tuberculosis of the Central Nervous System. Postgrad Med J (1999) 75(881):133-40. doi: 10.1136/pgmj.75.881.133

4. Leonard JM. Central Nervous System Tuberculosis. Microbiol Spectr (2017) 5 (2). doi: 10.1128/microbiolspec.TNMI7-0044-2017

5. Rom WN, Garay SM. Tuberculosis. 2 Ed. Philadelphia: Lippincott Williams \& Wilkins (2004).

6. Dallenga T, Schaible UE. Neutrophils in Tuberculosis-First Line of Defence or Booster of Disease and Targets for Host-Directed Therapy? Pathog Dis (2016) 74(3). doi: 10.1093/femspd/ftw012
anti-TNF- $\alpha$ may mitigate CNS-TB-associated neurological disabilities and death by reducing stroke occurrence. The use of other host-directed adjunctive therapy in CNS-TB, including MMP inhibition and inhibiting other neutrophil mediators, remains to be evaluated to further improve mortality and neurological outcomes.

\section{CONCLUSION}

Neutrophils play a critical role in driving CNS-TB immunopathology, with substantial evidence highlighting neutrophil-mediators in the cerebral inflammation, tissue destruction and thrombosis. Neutrophil antimicrobial arsenal such as NETs, serine proteases, MMPs and ROS are part of the innate immune response in CNS$\mathrm{TB}$, while neutrophils also cross-talk with other immune cell types, to contain $M$. $t b$ infection. However, neutrophil-mediated immune responses may also drive CNS-TB immunopathology. While the research of adjunctive therapies in CNS-TB using steroids, aspirin, and anti-TNF- $\alpha$ show promise, CNS-TB patients continue to develop severe neurological morbidity despite treatment. Given this limitation, a better understanding of the mechanisms underlying CNS-TB immunopathology in the context of neutrophils and MMPs may well lead to more effective hostdirected treatments.

\section{AUTHOR CONTRIBUTIONS}

$\mathrm{CO}$ and XYP conceived the review. XYP and FL wrote the first draft. XYP, FL, JF, and CO revised and re-drafted the article for critical intellectual content and approved the submitted version.

\section{FUNDING}

CO is supported by NMRC/TA/0042/2015, CSAINV17nov014 and National University Health System (NUHS/RO/2017/092/ $\mathrm{SU} / 01)$. XP is supported by a postgraduate scholarship from the Yong Loo Lin School of Medicine, National University of Singapore. JF acknowledges funding to his group from the Medical Research Council (UK), Rosetrees Trust and The Wellcome Trust for work described in the review.

7. Ong CW, Elkington PT, Brilha S, Ugarte-Gil C, Tome-Esteban MT, Tezera LB, et al. Neutrophil-Derived MMP-8 Drives AMPK-Dependent Matrix Destruction in Human Pulmonary Tuberculosis. PLoS Pathog (2015) 11(5): e1004917. doi: 10.1371/journal.ppat.1004917

8. Nwongbouwoh Muefong C, Owolabi O, Donkor S, Charalambous S, Bakuli A, Rachow A, et al. Neutrophils Contribute to Severity of Tuberculosis Pathology and Recovery From Lung Damage Pre- and Post-Treatment. Clin Infect Dis (2021). doi: 10.1093/cid/ciab729

9. Ong CW, Pabisiak PJ, Brilha S, Singh P, Roncaroli F, Elkington PT, et al. Complex Regulation of Neutrophil-Derived MMP-9 Secretion in Central Nervous System Tuberculosis. J Neuroinflamm (2017) 14(1):31. doi: 10.1186/s12974-017-0801-1

10. Green JA, Tran CT, Farrar JJ, Nguyen MT, Nguyen PH, Dinh SX, et al. Dexamethasone, Cerebrospinal Fluid Matrix Metalloproteinase Concentrations and Clinical Outcomes in Tuberculous Meningitis. PLoS One (2009) 4(9):e7277. doi: 10.1371/journal.pone.0007277 
11. Tsenova L, Mangaliso B, Muller G, Chen Y, Freedman VH, Stirling D, et al. Use of IMiD3, a Thalidomide Analog, as an Adjunct to Therapy for Experimental Tuberculous Meningitis. Antimicrob Agents Chemother (2002) 46(6):1887-95. doi: 10.1128/AAC.46.6.1887-1895.2002

12. Tsenova L, Sokol K, Freedman VH, Kaplan G. A Combination of Thalidomide Plus Antibiotics Protects Rabbits From Mycobacterial Meningitis-Associated Death. J Infect Dis (1998) 177(6):1563-72. doi: $10.1086 / 515327$

13. Tsenova L, Bergtold A, Freedman VH, Young RA, Kaplan G. Tumor Necrosis Factor Alpha is a Determinant of Pathogenesis and Disease Progression in Mycobacterial Infection in the Central Nervous System. Proc Natl Acad Sci USA (1999) 96(10):5657-62. doi: 10.1073/ pnas.96.10.5657

14. Braian C, Hogea V, Stendahl O. Mycobacterium Tuberculosis- Induced Neutrophil Extracellular Traps Activate Human Macrophages. J Innate Immun (2013) 5(6):591-602. doi: 10.1159/000348676

15. de Bont CM, Boelens WC, Pruijn GJM. NETosis, Complement, and Coagulation: A Triangular Relationship. Cell Mol Immunol (2019) 16 (1):19-27. doi: 10.1038/s41423-018-0024-0

16. Ducroux C, Di Meglio L, Loyau S, Delbosc S, Boisseau W, Deschildre C, et al. Thrombus Neutrophil Extracellular Traps Content Impair tPA-Induced Thrombolysis in Acute Ischemic Stroke. Stroke (2018) 49(3):754-7. doi: 10.1161/STROKEAHA.117.019896

17. Peto HM, Pratt RH, Harrington TA, LoBue PA, Armstrong LR. Epidemiology of Extrapulmonary Tuberculosis in the United States, 19932006. Clin Infect Dis (2009) 49(9):1350-7. doi: 10.1086/605559

18. Wilkinson RJ, Rohlwink U, Misra UK, van Crevel R, Mai NTH, Dooley KE, et al. Tuberculous Meningitis. Nat Rev Neurol (2017) 13(10):581-98. doi: 10.1038/nrneurol.2017.120

19. Nguyen DT, Agarwal S, Graviss EA. Trends of Tuberculosis Meningitis and Associated Mortality in Texas, 2010-2017, a Large Population-Based Analysis. PLoS One (2019) 14(2):e0212729. doi: 10.1371/journal.pone.0212729

20. UK Health Security Agency. Tuberculosis in England: 2020. London: UK Health Security Agency (2021).

21. Souza CH, Yamane A, Pandini JC, Ceretta LB, Ferraz F, da Luz GD, et al. Incidence of Tuberculous Meningitis in the State of Santa Catarina, Brazil. Rev Soc Bras Med Trop (2014) 47(4):483-9. doi: 10.1590/0037-8682-01222014

22. Ducomble T, Tolksdorf K, Karagiannis I, Hauer B, Brodhun B, Haas W, et al. The Burden of Extrapulmonary and Meningitis Tuberculosis: An Investigation of National Surveillance Data, Germany, 2002 to 2009. Euro Surveill (2013) 18(12). doi: 10.2807/ese.18.12.20436-en

23. Phypers M, Harris T, Power C. CNS Tuberculosis: A Longitudinal Analysis of Epidemiological and Clinical Features. Int J Tuberc Lung Dis (2006) 10 (1):99-103.

24. Rieder HL, Snider DE Jr, Cauthen GM. Extrapulmonary Tuberculosis in the United States. Am Rev Respir Dis (1990) 141(2):347-51. doi: 10.1164/ajrccm/ 141.2.347

25. Farer LS, Lowell AM, Meador MP. Extrapulmonary Tuberculosis in the United States. Am J Epidemiol (1979) 109(2):205-17. doi: 10.1093/ oxfordjournals.aje.a112675

26. Berenguer J, Moreno S, Laguna F, Vicente T, Adrados M, Ortega A, et al. Tuberculous Meningitis in Patients Infected With the Human Immunodeficiency Virus. N Engl J Med (1992) 326(10):668-72. doi: 10.1056/NEJM199203053261004

27. Dube MP, Holtom PD, Larsen RA. Tuberculous Meningitis in Patients With and Without Human Immunodeficiency Virus Infection. Am J Med (1992) 93(5):520-4. doi: 10.1016/0002-9343(92)90579-Z

28. Rana FS, Hawken MP, Mwachari C, Bhatt SM, Abdullah F, Ng'ang'a LW, et al. Autopsy Study of HIV-1-Positive and HIV-1-Negative Adult Medical Patients in Nairobi, Kenya. J Acquir Immune Defic Syndr (2000) 24(1):23-9. doi: 10.1097/00042560-200005010-00004

29. Schaller MA, Wicke F, Foerch C, Weidauer S. Central Nervous System Tuberculosis : Etiology, Clinical Manifestations and Neuroradiological Features. Clin Neuroradiol (2019) 29(1):3-18. doi: 10.1007/s00062-018-0726-9

30. Daniele B. Characteristics of Central Nervous System Tuberculosis in a LowIncidence Country: A Series of 20 Cases and a Review of the Literature. Jpn J Infect Dis (2014) 67(1):50-3. doi: 10.7883/yoken.67.50
31. Soria J, Metcalf T, Mori N, Newby RE, Montano SM, Huaroto L, et al. Mortality in Hospitalized Patients With Tuberculous Meningitis. BMC Infect Dis (2019) 19(1):9. doi: 10.1186/s12879-018-3633-4

32. Seddon JA, Shingadia D. Epidemiology and Disease Burden of Tuberculosis in Children: A Global Perspective. Infect Drug Resist (2014) 7:153-65. doi: $10.2147 /$ IDR.S45090

33. Miftode EG, Dorneanu OS, Leca DA, Juganariu G, Teodor A, Hurmuzache M, et al. Tuberculous Meningitis in Children and Adults: A 10-Year Retrospective Comparative Analysis. PLoS One (2015) 10(7):e0133477. doi: 10.1371/journal.pone.0133477

34. El Sahly HM, Teeter LD, Pan X, Musser JM, Graviss EA. Mortality Associated With Central Nervous System Tuberculosis. J Infect (2007) 55 (6):502-9. doi: 10.1016/j.jinf.2007.08.008

35. Jaipuriar RS, Garg RK, Rizvi I, Malhotra HS, Kumar N, Jain A, et al. Early Mortality Among Immunocompetent Patients of Tuberculous Meningitis: A Prospective Study. Am J Trop Med Hyg (2019) 101(2):357-61. doi: 10.4269/ ajtmh.19-0098

36. Tsai KS, Chang HL, Chien ST, Chen KL, Chen KH, Mai MH, et al. Childhood Tuberculosis: Epidemiology, Diagnosis, Treatment, and Vaccination. Pediatr Neonatol (2013) 54(5):295-302. doi: 10.1016/j.pedneo.2013.01.019

37. Qian X, Nguyen DT, Lyu J, Albers AE, Bi X, Graviss EA. Risk Factors for Extrapulmonary Dissemination of Tuberculosis and Associated Mortality During Treatment for Extrapulmonary Tuberculosis. Emerg Microbes Infect (2018) 7(1):102. doi: 10.1038/s41426-018-0106-1

38. Ong CW, Elkington PT, Friedland JS. Tuberculosis, Pulmonary Cavitation, and Matrix Metalloproteinases. Am J Respir Crit Care Med (2014) 190(1):918. doi: 10.1164/rccm.201311-2106PP

39. Rock RB, Olin M, Baker CA, Molitor TW, Peterson PK. Central Nervous System Tuberculosis: Pathogenesis and Clinical Aspects. Clin Microbiol Rev (2008) 21(2):243-61. doi: 10.1128/CMR.00042-07

40. Moule MG, Cirillo JD. Mycobacterium Tuberculosis Dissemination Plays a Critical Role in Pathogenesis. Front Cell Infect Microbiol (2020) 10:65. doi: $10.3389 /$ fcimb.2020.00065

41. Davis AG, Rohlwink UK, Proust A, Figaji AA, Wilkinson RJ. The Pathogenesis of Tuberculous Meningitis. J Leukoc Biol (2019) 105(2):26780. doi: 10.1002/JLB.MR0318-102R

42. Rich A. The Pathogenesis of Tuberculous Meningitis. Bull Johns Hopkins Hosp (1933) 52:5-37.

43. Blacklock JWSaMAG. Tuberculosis Meningitis: Problems in Pathogenesis and Treatment. J Pathol Bacteriol (1935) 40:489-502. doi: 10.1002/path.1700400308

44. Donald PR, Schaaf HS, Schoeman JF. Tuberculous Meningitis and Miliary Tuberculosis: The Rich Focus Revisited. J Infect (2005) 50(3):193-5. doi: 10.1016/j.jinf.2004.02.010

45. Macgregor AR, Green CA. Tuberculosis of the Central Nervous System, With Special Reference to Tuberculous Meningitis. J Pathol Bacteriol (1937) 45:613-45. doi: 10.1002/path.1700450312

46. Horne NW. Tuberculous Meningitis: Problems in Pathogenesis and Treatment. Edinb Med J (1951) 58(9):413-29.

47. Zaharie SD, Franken DJ, van der Kuip M, van Elsland S, de Bakker BS, Hagoort J, et al. The Immunological Architecture of Granulomatous Inflammation in Central Nervous System Tuberculosis. Tuberculosis (Edinb) (2020) 125:102016. doi: 10.1016/j.tube.2020.102016

48. Arvanitakis Z, Long RL, Hershfield ES, Manfreda J, Kabani A, Kunimoto D, et al. M. Tuberculosis Molecular Variation in CNS Infection: Evidence for Strain-Dependent Neurovirulence. Neurology (1998) 50(6):1827-32. doi: 10.1212/wnl.50.6.1827

49. Bidstrup C, Andersen PH, Skinhoj P, Andersen AB. Tuberculous Meningitis in a Country With a Low Incidence of Tuberculosis: Still a Serious Disease and a Diagnostic Challenge. Scand J Infect Dis (2002) 34(11):811-4. doi: 10.1080/0036554021000026938

50. Thwaites GE, van Toorn R, Schoeman J. Tuberculous Meningitis: More Questions, Still Too Few Answers. Lancet Neurol (2013) 12(10):999-1010. doi: 10.1016/S1474-4422(13)70168-6

51. Hopewell PC. A Clinical View of Tuberculosis. Radiol Clin North Am (1995) 33(4):641-53.

52. al-Deeb SM, Yaqub BA, Sharif HS, Motaery KR. Neurotuberculosis: A Review. Clin Neurol Neurosurg (1992) 94(Suppl):S30-3. doi: 10.1016/03038467(92)90014- $\mathrm{T}$ 
53. Garg RK, Malhotra HS, Jain A. Neuroimaging in Tuberculous Meningitis. Neurol India (2016) 64(2):219-27. doi: 10.4103/0028-3886.177608

54. Bernaerts A, Vanhoenacker FM, Parizel PM, Van Goethem JW, Van Altena $\mathrm{R}$, Laridon A, et al. Tuberculosis of the Central Nervous System: Overview of Neuroradiological Findings. Eur Radiol (2003) 13(8):1876-90. doi: 10.1007/ s00330-002-1608-7

55. Andronikou S, Smith B, Hatherhill M, Douis H, Wilmshurst J. Definitive Neuroradiological Diagnostic Features of Tuberculous Meningitis in Children. Pediatr Radiol (2004) 34(11):876-85. doi: 10.1007/s00247-004-1237-1

56. Botha H, Ackerman C, Candy S, Carr JA, Griffith-Richards S, Bateman KJ. Reliability and Diagnostic Performance of CT Imaging Criteria in the Diagnosis of Tuberculous Meningitis. PLoS One (2012) 7(6):e38982. doi: 10.1371/journal.pone.0038982

57. Raut T, Garg RK, Jain A, Verma R, Singh MK, Malhotra HS, et al. Hydrocephalus in Tuberculous Meningitis: Incidence, its Predictive Factors and Impact on the Prognosis. J Infect (2013) 66(4):330-7. doi: 10.1016/j.jinf.2012.12.009

58. Lammie GA, Hewlett RH, Schoeman JF, Donald PR. Tuberculous Cerebrovascular Disease: A Review. J Infect (2009) 59(3):156-66. doi: 10.1016/j.jinf.2009.07.012

59. Donald PR, Schoeman JF. Tuberculous Meningitis. N Engl J Med (2004) 351 (17):1719-20. doi: 10.1056/NEJMp048227

60. Kirwan DE, Chong DLW, Friedland JS. Platelet Activation and the Immune Response to Tuberculosis. Front Immunol (2021) 12:631696. doi: 10.3389/ fimmu.2021.631696

61. Girgis NI, Sultan Y, Farid Z, Mansour MM, Erian MW, Hanna LS, et al. Tuberculosis Meningitis, Abbassia Fever Hospital-Naval Medical Research Unit No. 3-Cairo, Egypt, From 1976 to 1996. Am J Trop Med Hyg (1998) 58 (1):28-34. doi: 10.4269/ajtmh.1998.58.28

62. Thwaites GE, Nguyen DB, Nguyen HD, Hoang TQ, Do TT, Nguyen TC, et al. Dexamethasone for the Treatment of Tuberculous Meningitis in Adolescents and Adults. NEngl JMed (2004) 351(17):1741-51. doi: 10.1056/NEJMoa040573

63. Katti MK. Pathogenesis, Diagnosis, Treatment, and Outcome Aspects of Cerebral Tuberculosis. Med Sci Monit (2004) 10(9):RA215-29.

64. Thwaites GE, Tran TH. Tuberculous Meningitis: Many Questions, Too Few Answers. Lancet Neurol (2005) 4(3):160-70. doi: 10.1016/S1474-4422(05) 70019-3

65. Medical Research Council, Streptomycin in Tuberculosis Trials Committee. Streptomycin Treatment of Tuberculous Meningitis. Lancet (1948) 1948 (6503):582-96.

66. Jacobs RF, Sunakorn P, Chotpitayasunonah T, Pope S, Kelleher K. Intensive Short Course Chemotherapy for Tuberculous Meningitis. Pediatr Infect Dis J (1992) 11(3):194-8. doi: 10.1097/00006454-199203000-00004

67. Kim TK, Chang KH, Kim CJ, Goo JM, Kook MC, Han MH. Intracranial Tuberculoma: Comparison of MR With Pathologic Findings. AJNR Am J Neuroradiol (1995) 16(9):1903-8.

68. Wasay M, Kheleani BA, Moolani MK, Zaheer J, Pui M, Hasan S, et al. Brain CT and MRI Findings in 100 Consecutive Patients With Intracranial Tuberculoma. J Neuroimaging (2003) 13(3):240-7. doi: 10.1111/j.15526569.2003.tb00185.x

69. DeLance AR, Safaee M, Oh MC, Clark AJ, Kaur G, Sun MZ, et al. Tuberculoma of the Central Nervous System. J Clin Neurosci (2013) 20 (10):1333-41. doi: 10.1016/j.jocn.2013.01.008

70. Chakraborti S, Mahadevan A, Govindan A, Nagarathna S, Santosh V, Yasha TC, et al. Clinicopathological Study of Tuberculous Brain Abscess. Pathol Res Pract (2009) 205(12):815-22. doi: 10.1016/j.prp.2009.05.012

71. Kumar R, Pandey CK, Bose N, Sahay S. Tuberculous Brain Abscess: Clinical Presentation, Pathophysiology and Treatment (in Children). Childs Nerv Syst (2002) 18(3-4):118-23. doi: 10.1007/s00381-002-0575-2

72. Whitener DR. Tuberculous Brain Abscess. Report of a Case and Review of the Literature. Arch Neurol (1978) 35(3):148-55. doi: 10.1001/archneur. 1978.00500270030007

73. de Vries HE, Kuiper J, de Boer AG, Van Berkel TJ, Breimer DD. The BloodBrain Barrier in Neuroinflammatory Diseases. Pharmacol Rev (1997) 49 (2):143-55.

74. Nguyen L, Pieters J. The Trojan Horse: Survival Tactics of Pathogenic Mycobacteria in Macrophages. Trends Cell Biol (2005) 15(5):269-76. doi: $10.1016 /$ j.tcb.2005.03.009
75. Be NA, Kim KS, Bishai WR, Jain SK. Pathogenesis of Central Nervous System Tuberculosis. Curr Mol Med (2009) 9(2):94-9. doi: 10.2174/ 156652409787581655

76. Jain SK, Paul-Satyaseela M, Lamichhane G, Kim KS, Bishai WR. Mycobacterium Tuberculosis Invasion and Traversal Across an In Vitro Human Blood-Brain Barrier as a Pathogenic Mechanism for Central Nervous System Tuberculosis. J Infect Dis (2006) 193(9):1287-95. doi: $10.1086 / 502631$

77. Be NA, Bishai WR, Jain SK. Role of Mycobacterium Tuberculosis pknD in the Pathogenesis of Central Nervous System Tuberculosis. BMC Microbiol (2012) 12:7. doi: 10.1186/1471-2180-12-7

78. Brilha S, Ong CWM, Weksler B, Romero N, Couraud PO, Friedland JS. Matrix Metalloproteinase-9 Activity and a Downregulated Hedgehog Pathway Impair Blood-Brain Barrier Function in an In Vitro Model of CNS Tuberculosis. Sci Rep (2017) 7(1):16031. doi: 10.1038/s41598-01716250-3

79. Francisco NM, Hsu NJ, Keeton R, Randall P, Sebesho B, Allie N, et al. TNFDependent Regulation and Activation of Innate Immune Cells are Essential for Host Protection Against Cerebral Tuberculosis. J Neuroinflamm (2015) 12:125. doi: 10.1186/s12974-015-0345-1

80. Ong CWM, Fox K, Ettorre A, Elkington PT, Friedland JS. Hypoxia Increases Neutrophil-Driven Matrix Destruction After Exposure to Mycobacterium Tuberculosis. Sci Rep (2018) 8(1):11475. doi: 10.1038/s41598-018-29659-1

81. Sawant KV, McMurray DN. Guinea Pig Neutrophils Infected With Mycobacterium Tuberculosis Produce Cytokines Which Activate Alveolar Macrophages in Noncontact Cultures. Infect Immun (2007) 75(4):1870-7. doi: 10.1128/IAI.00858-06

82. Hilda JN, Das SD. TLR Stimulation of Human Neutrophils Lead to Increased Release of MCP-1, MIP-1alpha, IL-1beta, IL-8 and TNF During Tuberculosis. Hum Immunol (2016) 77(1):63-7. doi: 10.1016/ j.humimm.2015.10.005

83. Hilda JN, Narasimhan M, Das SD. Neutrophils From Pulmonary Tuberculosis Patients Show Augmented Levels of Chemokines MIP1alpha, IL-8 and MCP-1 Which Further Increase Upon In Vitro Infection With Mycobacterial Strains. Hum Immunol (2014) 75(8):914-22. doi: 10.1016/j.humimm.2014.06.020

84. Cannas S, Molicotti P, Bua A, Usai D, Sechi LA, Scanu AM, et al. Interaction Between Mycobacterium Tuberculosis, Mycobacterium Bovis, Mycobacterium Avium Subspecies Paratuberculosis With the Enteric Glia and Microglial Cells. Gut Pathog (2011) 3:19. doi: 10.1186/1757-4749-3-19

85. Fleischmann J, Golde DW, Weisbart RH, Gasson JC. GranulocyteMacrophage Colony-Stimulating Factor Enhances Phagocytosis of Bacteria by Human Neutrophils. Blood (1986) 68(3):708-11. doi: 10.1182/ blood.V68.3.708.708

86. Blomgran R, Ernst JD. Lung Neutrophils Facilitate Activation of Naive AntigenSpecific CD4+ T Cells During Mycobacterium Tuberculosis Infection. J Immunol (2011) 186(12):7110-9. doi: 10.4049/jimmunol.1100001

87. Kang DD, Lin Y, Moreno JR, Randall TD, Khader SA. Profiling Early Lung Immune Responses in the Mouse Model of Tuberculosis. PLoS One (2011) 6 (1):e16161. doi: 10.1371/journal.pone.0016161

88. Blomgran R, Desvignes L, Briken V, Ernst JD. Mycobacterium Tuberculosis Inhibits Neutrophil Apoptosis, Leading to Delayed Activation of Naive CD4 T Cells. Cell Host Microbe (2012) 11(1):81-90. doi: 10.1016/ j.chom.2011.11.012

89. Flower RJ. Prostaglandins, Bioassay and Inflammation. Br J Pharmacol (2006) 147 Suppl 1:S182-92. doi: 10.1038/sj.bjp.0706506

90. Medeiros AI, Silva CL, Malheiro A, Maffei CM, Faccioli LH. Leukotrienes are Involved in Leukocyte Recruitment Induced by Live Histoplasma Capsulatum or by the Beta-Glucan Present in Their Cell Wall. Br J Pharmacol (1999) 128(7):1529-37. doi: 10.1038/sj.bjp.0702912

91. Nourshargh S. Mechanisms of Neutrophil and Eosinophil Accumulation In Vivo. Am Rev Respir Dis (1993) 148(6 Pt 2):S60-4. doi: 10.1164/ajrccm/ 148.6_Pt_2.S60

92. Serhan CN, Chiang N, Van Dyke TE. Resolving Inflammation: Dual AntiInflammatory and Pro-Resolution Lipid Mediators. Nat Rev Immunol (2008) 8(5):349-61. doi: 10.1038/nri2294

93. Lemos HP, Grespan R, Vieira SM, Cunha TM, Verri WA Jr, Fernandes KS, et al. Prostaglandin Mediates IL-23/IL-17-Induced Neutrophil Migration in 
Inflammation by Inhibiting IL-12 and IFNgamma Production. Proc Natl Acad Sci U S A (2009) 106(14):5954-9. doi: 10.1073/pnas.0812782106

94. Lammermann T. In the Eye of the Neutrophil Swarm-Navigation Signals That Bring Neutrophils Together in Inflamed and Infected Tissues. J Leukoc Biol (2016) 100(1):55-63. doi: 10.1189/jlb.1MR0915-403

95. de Oliveira S, Rosowski EE, Huttenlocher A. Neutrophil Migration in Infection and Wound Repair: Going Forward in Reverse. Nat Rev Immunol (2016) 16(6):378-91. doi: 10.1038/nri.2016.49

96. Palmblad JE, Lerner R. Leukotriene B4-Induced Hyperadhesiveness of Endothelial Cells for Neutrophils: Relation to CD54. Clin Exp Immunol (1992) 90(2):300-4. doi: 10.1111/j.1365-2249.1992.tb07946.x

97. Vilaplana C, Marzo E, Tapia G, Diaz J, Garcia V, Cardona PJ. Ibuprofen Therapy Resulted in Significantly Decreased Tissue Bacillary Loads and Increased Survival in a New Murine Experimental Model of Active Tuberculosis. J Infect Dis (2013) 208(2):199-202. doi: 10.1093/infdis/jit152

98. Nathan C. Neutrophils and Immunity: Challenges and Opportunities. Nat Rev Immunol (2006) 6(3):173-82. doi: 10.1038/nri1785

99. Dallenga T, Repnik U, Corleis B, Eich J, Reimer R, Griffiths GW, et al. M. Tuberculosis-Induced Necrosis of Infected Neutrophils Promotes Bacterial Growth Following Phagocytosis by Macrophages. Cell Host Microbe (2017) 22(4):519-30 e3. doi: 10.1016/j.chom.2017.09.003

100. Corleis B, Korbel D, Wilson R, Bylund J, Chee R, Schaible UE. Escape of Mycobacterium Tuberculosis From Oxidative Killing by Neutrophils. Cell Microbiol (2012) 14(7):1109-21. doi: 10.1111/j.1462-5822.2012.01783.x

101. Dallenga T, Linnemann L, Paudyal B, Repnik U, Griffiths G, Schaible UE. Targeting Neutrophils for Host-Directed Therapy to Treat Tuberculosis. Int J Med Microbiol (2018) 308(1):142-7. doi: 10.1016/j.ijmm.2017.10.001

102. Perskvist N, Long M, Stendahl O, Zheng L. Mycobacterium Tuberculosis Promotes Apoptosis in Human Neutrophils by Activating Caspase- 3 and Altering Expression of Bax/Bcl-xL via an Oxygen-Dependent Pathway. J Immunol (2002) 168(12):6358-65. doi: 10.4049/jimmunol.168.12.6358

103. Persson YA, Blomgran-Julinder R, Rahman S, Zheng L, Stendahl O. Mycobacterium Tuberculosis-Induced Apoptotic Neutrophils Trigger a Pro-Inflammatory Response in Macrophages Through Release of Heat Shock Protein 72, Acting in Synergy With the Bacteria. Microbes Infect (2008) 10(3):233-40. doi: 10.1016/j.micinf.2007.11.007

104. Tan BH, Meinken C, Bastian M, Bruns H, Legaspi A, Ochoa MT, et al. Macrophages Acquire Neutrophil Granules for Antimicrobial Activity Against Intracellular Pathogens. J Immunol (2006) 177(3):1864-71. doi: 10.4049/jimmunol.177.3.1864

105. Cooper AM, Dalton DK, Stewart TA, Griffin JP, Russell DG, Orme IM. Disseminated Tuberculosis in Interferon Gamma Gene-Disrupted Mice. J Exp Med (1993) 178(6):2243-7. doi: 10.1084/jem.178.6.2243

106. Keane J, Gershon S, Wise RP, Mirabile-Levens E, Kasznica J, Schwieterman WD, et al. Tuberculosis Associated With Infliximab, a Tumor Necrosis Factor Alpha-Neutralizing Agent. N Engl J Med (2001) 345(15):1098-104. doi: 10.1056/NEJMoa011110

107. Botha T, Ryffel B. Reactivation of Latent Tuberculosis Infection in TNFDeficient Mice. J Immunol (2003) 171(6):3110-8. doi: 10.4049/ jimmunol.171.6.3110

108. Ehlers S, Kutsch S, Ehlers EM, Benini J, Pfeffer K. Lethal Granuloma Disintegration in Mycobacteria-Infected TNFRp55-/- Mice is Dependent on T Cells and IL-12. J Immunol (2000) 165(1):483-92. doi: 10.4049/ jimmunol.165.1.483

109. Saunders BM, Frank AA, Orme IM, Cooper AM. CD4 is Required for the Development of a Protective Granulomatous Response to Pulmonary Tuberculosis. Cell Immunol (2002) 216(1-2):65-72. doi: 10.1016/S00088749(02)00510-5

110. Nandi B, Behar SM. Regulation of Neutrophils by Interferon-Gamma Limits Lung Inflammation During Tuberculosis Infection. J Exp Med (2011) 208 (11):2251-62. doi: 10.1084/jem.20110919

111. MacMicking JD, Taylor GA, McKinney JD. Immune Control of Tuberculosis by IFN-Gamma-Inducible LRG-47. Science (2003) 302(5645):654-9. doi: $10.1126 /$ science. 1088063

112. Gutierrez MG, Master SS, Singh SB, Taylor GA, Colombo MI, Deretic V. Autophagy is a Defense Mechanism Inhibiting BCG and Mycobacterium Tuberculosis Survival in Infected Macrophages. Cell (2004) 119(6):753-66. doi: 10.1016/j.cell.2004.11.038
113. Mishra BB, Rathinam VA, Martens GW, Martinot AJ, Kornfeld H, Fitzgerald KA, et al. Nitric Oxide Controls the Immunopathology of Tuberculosis by Inhibiting NLRP3 Inflammasome-Dependent Processing of IL-1beta. Nat Immunol (2013) 14(1):52-60. doi: 10.1038/ni.2474

114. Brinkmann V, Reichard U, Goosmann C, Fauler B, Uhlemann Y, Weiss DS, et al. Neutrophil Extracellular Traps Kill Bacteria. Science (2004) 303 (5663):1532-5. doi: 10.1126/science.1092385

115. Ramos-Kichik V, Mondragon-Flores R, Mondragon-Castelan M, GonzalezPozos S, Muniz-Hernandez S, Rojas-Espinosa O, et al. Neutrophil Extracellular Traps are Induced by Mycobacterium Tuberculosis. Tuberculosis (Edinb) (2009) 89(1):29-37. doi: 10.1016/j.tube.2008.09.009

116. Takei H, Araki A, Watanabe H, Ichinose A, Sendo F. Rapid Killing of Human Neutrophils by the Potent Activator Phorbol 12-Myristate 13-Acetate (PMA) Accompanied by Changes Different From Typical Apoptosis or Necrosis. J Leukoc Biol (1996) 59(2):229-40. doi: 10.1002/jlb.59.2.229

117. Jorch SK, Kubes P. An Emerging Role for Neutrophil Extracellular Traps in Noninfectious Disease. Nat Med (2017) 23(3):279-87. doi: 10.1038/nm.4294

118. Kaplan MJ, Radic M. Neutrophil Extracellular Traps: Double-Edged Swords of Innate Immunity. J Immunol (2012) 189(6):2689-95. doi: 10.4049/ jimmunol.1201719

119. Metzler KD, Goosmann C, Lubojemska A, Zychlinsky A, Papayannopoulos V. A Myeloperoxidase-Containing Complex Regulates Neutrophil Elastase Release and Actin Dynamics During NETosis. Cell Rep (2014) 8(3):883-96. doi: 10.1016/j.celrep.2014.06.044

120. Clark SR, Ma AC, Tavener SA, McDonald B, Goodarzi Z, Kelly MM, et al. Platelet TLR4 Activates Neutrophil Extracellular Traps to Ensnare Bacteria in Septic Blood. Nat Med (2007) 13(4):463-9. doi: 10.1038/nm1565

121. Pilsczek FH, Salina D, Poon KK, Fahey C, Yipp BG, Sibley CD, et al. A Novel Mechanism of Rapid Nuclear Neutrophil Extracellular Trap Formation in Response to Staphylococcus Aureus. J Immunol (2010) 185(12):7413-25. doi: 10.4049/jimmunol.1000675

122. Yipp BG, Petri B, Salina D, Jenne CN, Scott BN, Zbytnuik LD, et al. Infection-Induced NETosis is a Dynamic Process Involving Neutrophil Multitasking In Vivo. Nat Med (2012) 18(9):1386-93. doi: 10.1038/nm.2847

123. Rochael NC, Guimaraes-Costa AB, Nascimento MT, DeSouza-Vieira TS, Oliveira MP, Garcia e Souza LF, et al. Classical ROS-Dependent and Early/ Rapid ROS-Independent Release of Neutrophil Extracellular Traps Triggered by Leishmania Parasites. Sci Rep (2015) 5:18302. doi: 10.1038/srep18302

124. Slaba I, Wang J, Kolaczkowska E, McDonald B, Lee WY, Kubes P. Imaging the Dynamic Platelet-Neutrophil Response in Sterile Liver Injury and Repair in Mice. Hepatology (2015) 62(5):1593-605. doi: 10.1002/hep.28003

125. Azzouz D, Khan MA, Sweezey N, Palaniyar N. Two-In-One: UV Radiation Simultaneously Induces Apoptosis and NETosis. Cell Death Discov (2018) 4:51. doi: 10.1038/s41420-018-0048-3

126. Berry MP, Graham CM, McNab FW, Xu Z, Bloch SA, Oni T, et al. An Interferon-Inducible Neutrophil-Driven Blood Transcriptional Signature in Human Tuberculosis. Nature (2010) 466(7309):973-7. doi: 10.1038/ nature 09247

127. Moreira-Teixeira L, Stimpson PJ, Stavropoulos E, Hadebe S, Chakravarty P, Ioannou M, et al. Type I IFN Exacerbates Disease in TuberculosisSusceptible Mice by Inducing Neutrophil-Mediated Lung Inflammation and NETosis. Nat Commun (2020) 11(1):5566. doi: 10.1038/s41467-02019412-6

128. Ravindran M, Khan MA, Palaniyar N. Neutrophil Extracellular Trap Formation: Physiology, Pathology, and Pharmacology. Biomolecules (2019) 9(8):365. doi: 10.3390/biom9080365

129. Kolaczkowska E, Jenne CN, Surewaard BG, Thanabalasuriar A, Lee WY, Sanz MJ, et al. Molecular Mechanisms of NET Formation and Degradation Revealed by Intravital Imaging in the Liver Vasculature. Nat Commun (2015) 6:6673. doi: $10.1038 /$ ncomms 7673

130. Erpenbeck L, Schon MP. Neutrophil Extracellular Traps: Protagonists of Cancer Progression? Oncogene (2017) 36(18):2483-90. doi: 10.1038/ onc.2016.406

131. Khan MA, D'Ovidio A, Tran H, Palaniyar N. Anthracyclines Suppress Both NADPH Oxidase- Dependent and -Independent NETosis in Human Neutrophils. Cancers (Basel) (2019) 11(9):1328. doi: 10.3390/cancers11091328

132. Sollberger G, Choidas A, Burn GL, Habenberger P, Di Lucrezia R, Kordes S, et al. Gasdermin D Plays a Vital Role in the Generation of Neutrophil 
Extracellular Traps. Sci Immunol (2018) 3(26). doi: 10.1126/ sciimmunol.aar6689

133. Guyot N, Wartelle J, Malleret L, Todorov AA, Devouassoux G, Pacheco Y, et al. Neutrophil Elastase, and Proteinase 3 Cause Severe Lung Damage and Emphysema. Am J Pathol (2014) 184(8):2197-210. doi: 10.1016/ j.ajpath.2014.04.015

134. Marais S, Lai RPJ, Wilkinson KA, Meintjes G, O'Garra A, Wilkinson RJ. Inflammasome Activation Underlying Central Nervous System Deterioration in HIV-Associated Tuberculosis. J Infect Dis (2017) 215 (5):677-86. doi: 10.1093/infdis/jiw561

135. Chen H, Song YS, Chan PH. Inhibition of NADPH Oxidase is Neuroprotective After Ischemia-Reperfusion. J Cereb Blood Flow Metab (2009) 29(7):1262-72. doi: 10.1038/jcbfm.2009.47

136. Kvietys PR, Granger DN. Role of Reactive Oxygen and Nitrogen Species in the Vascular Responses to Inflammation. Free Radic Biol Med (2012) 52 (3):556-92. doi: 10.1016/j.freeradbiomed.2011.11.002

137. Krizbai IA, Bauer H, Bresgen N, Eckl PM, Farkas A, Szatmari E, et al. Effect of Oxidative Stress on the Junctional Proteins of Cultured Cerebral Endothelial Cells. Cell Mol Neurobiol (2005) 25(1):129-39. doi: 10.1007/ s10571-004-1378-7

138. Hilda JN, Das S, Tripathy SP, Hanna LE. Role of Neutrophils in Tuberculosis: A Bird's Eye View. Innate Immun (2020) 26(4):240-7. doi: $10.1177 / 1753425919881176$

139. Mastroianni CM, Lancella L, Mengoni F, Lichtner M, Santopadre P, D'Agostino C, et al. Chemokine Profiles in the Cerebrospinal Fluid (CSF) During the Course of Pyogenic and Tuberculous Meningitis. Clin Exp Immunol (1998) 114(2):210-4. doi: 10.1046/j.1365-2249.1998.00698.x

140. Singh S, Maniakis-Grivas G, Singh UK, Asher RM, Mauri F, Elkington PT, et al. Interleukin-17 Regulates Matrix Metalloproteinase Activity in Human Pulmonary Tuberculosis. J Pathol (2018) 244(3):311-22. doi: 10.1002/path.5013

141. Marais S, Wilkinson KA, Lesosky M, Coussens AK, Deffur A, Pepper DJ, et al. Neutrophil-Associated Central Nervous System Inflammation in Tuberculous Meningitis Immune Reconstitution Inflammatory Syndrome. Clin Infect Dis (2014) 59(11):1638-47. doi: 10.1093/cid/ciu641

142. Lin PL, Plessner HL, Voitenok NN, Flynn JL. Tumor Necrosis Factor and Tuberculosis. J Investig Dermatol Symp Proc (2007) 12(1):22-5. doi: 10.1038/ sj.jidsymp. 5650027

143. Francisco NM, Allie N, Sebesho B, Ryffel B, Jacobs M. Complete Ablation of Tumor Necrosis Factor Decreases the Production of IgA, IgG, and IgM in Experimental Central Nervous System Tuberculosis. Iran J Basic Med Sci (2020) 23(5):680-90. doi: 10.22038/ijbms.2020.37947.9021

144. Hsu NJ, Francisco NM, Keeton R, Allie N, Quesniaux VF, Ryffel B, et al. Myeloid and T Cell-Derived TNF Protects Against Central Nervous System Tuberculosis. Front Immunol (2017) 8:180. doi: 10.3389/fimmu.2017.00180

145. Hot A, Lenief V, Miossec P. Combination of IL-17 and TNFalpha Induces a Pro-Inflammatory, Pro-Coagulant and Pro-Thrombotic Phenotype in Human Endothelial Cells. Ann Rheum Dis (2012) 71(5):768-76. doi: 10.1136/annrheumdis-2011-200468

146. Parks WC, Wilson CL, Lopez-Boado YS. Matrix Metalloproteinases as Modulators of Inflammation and Innate Immunity. Nat Rev Immunol (2004) 4(8):617-29. doi: 10.1038/nri1418

147. Chandler S, Miller KM, Clements JM, Lury J, Corkill D, Anthony DC, et al. Matrix Metalloproteinases, Tumor Necrosis Factor and Multiple Sclerosis: An Overview. J Neuroimmunol (1997) 72(2):155-61. doi: 10.1016/S01655728(96)00179-8

148. Yang Y, Estrada EY, Thompson JF, Liu W, Rosenberg GA. Matrix Metalloproteinase-Mediated Disruption of Tight Junction Proteins in Cerebral Vessels is Reversed by Synthetic Matrix Metalloproteinase Inhibitor in Focal Ischemia in Rat. J Cereb Blood Flow Metab (2007) 27 (4):697-709. doi: 10.1038/sj.jcbfm.9600375

149. Zhang Q, Zheng M, Betancourt CE, Liu L, Sitikov A, Sladojevic N, et al. Increase in Blood-Brain Barrier (BBB) Permeability Is Regulated by MMP3 via the ERK Signaling Pathway. Oxid Med Cell Longev (2021) 2021:6655122. doi: 10.1155/2021/6655122

150. Kahari VM, Saarialho-Kere U. Matrix Metalloproteinases in Skin. Exp Dermatol (1997) 6(5):199-213. doi: 10.1111/j.1600-0625.1997.tb00164.x

151. Ashworth JL, Murphy G, Rock MJ, Sherratt MJ, Shapiro SD, Shuttleworth CA, et al. Fibrillin Degradation by Matrix Metalloproteinases: Implications for Connective Tissue Remodelling. Biochem J (1999) 340( Pt 1):171-81. doi: $10.1042 / b j 3400171$

152. Rauch U. Extracellular Matrix Components Associated With Remodeling Processes in Brain. Cell Mol Life Sci (2004) 61(16):2031-45. doi: 10.1007/ s00018-004-4043-x

153. Sang QX, Birkedal-Hansen H, Van Wart HE. Proteolytic and nonProteolytic Activation of Human Neutrophil Progelatinase B. Biochim Biophys Acta (1995) 1251(2):99-108. doi: 10.1016/0167-4838(95)00086-A

154. Schonbeck U, Mach F, Libby P. Generation of Biologically Active IL-1 Beta by Matrix Metalloproteinases: A Novel Caspase-1-Independent Pathway of IL-1 Beta Processing. J Immunol (1998) 161(7):3340-6.

155. Gurney KJ, Estrada EY, Rosenberg GA. Blood-Brain Barrier Disruption by Stromelysin-1 Facilitates Neutrophil Infiltration in Neuroinflammation. Neurobiol Dis (2006) 23(1):87-96. doi: 10.1016/j.nbd.2006.02.006

156. Liu J, Jin X, Liu KJ, Liu W. Matrix Metalloproteinase-2-Mediated Occludin Degradation and Caveolin-1-Mediated Claudin-5 Redistribution Contribute to Blood-Brain Barrier Damage in Early Ischemic Stroke Stage. J Neurosci (2012) 32(9):3044-57. doi: 10.1523/JNEUROSCI.6409-11.2012

157. Lochter A, Galosy S, Muschler J, Freedman N, Werb Z, Bissell MJ. Matrix Metalloproteinase Stromelysin-1 Triggers a Cascade of Molecular Alterations That Leads to Stable Epithelial-to-Mesenchymal Conversion and a Premalignant Phenotype in Mammary Epithelial Cells. J Cell Biol (1997) 139(7):1861-72. doi: 10.1083/jcb.139.7.1861

158. McGuire JK, Li Q, Parks WC. Matrilysin (Matrix Metalloproteinase-7) Mediates E-Cadherin Ectodomain Shedding in Injured Lung Epithelium. Am J Pathol (2003) 162(6):1831-43. doi: 10.1016/S0002-9440(10)64318-0

159. Yu Q, Stamenkovic I. Cell Surface-Localized Matrix Metalloproteinase-9 Proteolytically Activates TGF-Beta and Promotes Tumor Invasion and Angiogenesis. Genes Dev (2000) 14(2):163-76. doi: 10.1101/gad.14.2.163

160. McQuibban GA, Gong JH, Tam EM, McCulloch CA, Clark-Lewis I, Overall CM. Inflammation Dampened by Gelatinase A Cleavage of Monocyte Chemoattractant Protein-3. Science (2000) 289(5482):1202-6. doi: 10.1126/ science.289.5482.1202

161. Zhang K, McQuibban GA, Silva C, Butler GS, Johnston JB, Holden J, et al. HIV-Induced Metalloproteinase Processing of the Chemokine Stromal Cell Derived Factor-1 Causes Neurodegeneration. Nat Neurosci (2003) 6 (10):1064-71. doi: 10.1038/nn1127

162. Haro H, Crawford HC, Fingleton B, Shinomiya K, Spengler DM, Matrisian LM. Matrix Metalloproteinase-7-Dependent Release of Tumor Necrosis Factor-Alpha in a Model of Herniated Disc Resorption. J Clin Invest (2000) 105(2):143-50. doi: 10.1172/JCI7091

163. Churg A, Wang RD, Tai H, Wang X, Xie C, Dai J, et al. Macrophage Metalloelastase Mediates Acute Cigarette Smoke-Induced Inflammation via Tumor Necrosis Factor-Alpha Release. Am J Respir Crit Care Med (2003) 167 (8):1083-9. doi: 10.1164/rccm.200212-1396OC

164. Sternlicht MD, Werb Z. How Matrix Metalloproteinases Regulate Cell Behavior. Annu Rev Cell Dev Biol (2001) 17:463-516. doi: 10.1146/ annurev.cellbio.17.1.463

165. Mackay AR, Hartzler JL, Pelina MD, Thorgeirsson UP. Studies on the Ability of $65-\mathrm{kDa}$ and $92-\mathrm{kDa}$ Tumor Cell Gelatinases to Degrade Type IV Collagen. J Biol Chem (1990) 265(35):21929-34. doi: 10.1016/S0021-9258(18)45827-9

166. Brooks PC, Stromblad S, Sanders LC, von Schalscha TL, Aimes RT, StetlerStevenson WG, et al. Localization of Matrix Metalloproteinase MMP-2 to the Surface of Invasive Cells by Interaction With Integrin Alpha V Beta 3. Cell (1996) 85(5):683-93. doi: 10.1016/S0092-8674(00)81235-0

167. Yu WH, Woessner JF Jr. Heparan Sulfate Proteoglycans as Extracellular Docking Molecules for Matrilysin (Matrix Metalloproteinase 7). J Biol Chem (2000) 275(6):4183-91. doi: 10.1074/jbc.275.6.4183

168. Yu WH, Woessner JF Jr, McNeish JD, Stamenkovic I. CD44 Anchors the Assembly of Matrilysin/MMP-7 With Heparin-Binding Epidermal Growth Factor Precursor and ErbB4 and Regulates Female Reproductive Organ Remodeling. Genes Dev (2002) 16(3):307-23. doi: 10.1101/gad.925702

169. Loffek S, Schilling O, Franzke CW. Series "Matrix Metalloproteinases in Lung Health and Disease": Biological Role of Matrix Metalloproteinases: A Critical Balance. Eur Respir J (2011) 38(1):191-208. doi: 10.1183/09031936.00146510

170. Visse R, Nagase H. Matrix Metalloproteinases and Tissue Inhibitors of Metalloproteinases: Structure, Function, and Biochemistry. Circ Res (2003) 92(8):827-39. doi: 10.1161/01.RES.0000070112.80711.3D 
171. Murphy G. Tissue Inhibitors of Metalloproteinases. Genome Biol (2011) 12 (11):233. doi: 10.1186/gb-2011-12-11-233

172. Candelario-Jalil E, Yang Y, Rosenberg GA. Diverse Roles of Matrix Metalloproteinases and Tissue Inhibitors of Metalloproteinases in Neuroinflammation and Cerebral Ischemia. Neuroscience (2009) 158 (3):983-94. doi: 10.1016/j.neuroscience.2008.06.025

173. Rosenberg GA. Matrix Metalloproteinases in Neuroinflammation. Glia (2002) 39(3):279-91. doi: 10.1002/glia.10108

174. Tayebjee MH, Nadar S, Blann AD, Gareth Beevers D, MacFadyen RJ, Lip GY. Matrix Metalloproteinase-9 and Tissue Inhibitor of Metalloproteinase-1 in Hypertension and Their Relationship to Cardiovascular Risk and Treatment: A Substudy of the Anglo-Scandinavian Cardiac Outcomes Trial (ASCOT). Am J Hypertens (2004) 17(9):764-9. doi: 10.1016/S0895-7061(04)00855-6

175. Leppert D, Leib SL, Grygar C, Miller KM, Schaad UB, Hollander GA. Matrix Metalloproteinase (MMP)-8 and MMP-9 in Cerebrospinal Fluid During Bacterial Meningitis: Association With Blood-Brain Barrier Damage and Neurological Sequelae. Clin Infect Dis (2000) 31(1):80-4. doi: 10.1086/ 313922

176. Green JA, Elkington PT, Pennington CJ, Roncaroli F, Dholakia S, Moores RC, et al. Mycobacterium Tuberculosis Upregulates Microglial Matrix Metalloproteinase-1 and -3 Expression and Secretion via NF-kappaB- and Activator Protein-1-Dependent Monocyte Networks. J Immunol (2010) 184 (11):6492-503. doi: 10.4049/jimmunol.0903811

177. Green JA, Friedland JS. Astrocyte-Leucocyte Interactions and the Mechanisms Regulating Matrix Degradation in CNS Tuberculosis. Biochem Soc Trans (2007) 35(Pt 4):686-8. doi: 10.1042/BST0350686

178. Nuttall RK, Silva C, Hader W, Bar-Or A, Patel KD, Edwards DR, et al. Metalloproteinases are Enriched in Microglia Compared With Leukocytes and They Regulate Cytokine Levels in Activated Microglia. Glia (2007) 55 (5):516-26. doi: 10.1002/glia.20478

179. Woo MS, Park JS, Choi IY, Kim WK, Kim HS. Inhibition of MMP-3 or -9 Suppresses Lipopolysaccharide-Induced Expression of Proinflammatory Cytokines and iNOS in Microglia. J Neurochem (2008) 106(2):770-80. doi: 10.1111/j.1471-4159.2008.05430.x

180. Sabir N, Hussain T, Mangi MH, Zhao D, Zhou X. Matrix Metalloproteinases: Expression, Regulation and Role in the Immunopathology of Tuberculosis. Cell Prolif (2019) 52(4):e12649. doi: 10.1111/cpr.12649

181. Hernandez-Pando R, Orozco H, Arriaga K, Pavon L, Rook G. Treatment With BB-94, a Broad Spectrum Inhibitor of Zinc-Dependent Metalloproteinases, Causes Deviation of the Cytokine Profile Towards Type-2 in Experimental Pulmonary Tuberculosis in Balb/c Mice. Int J Exp Pathol (2000) 81(3):199-209. doi: 10.1046/j.1365-2613.2000.00152.x

182. Izzo AA, Izzo LS, Kasimos J, Majka S. A Matrix Metalloproteinase Inhibitor Promotes Granuloma Formation During the Early Phase of Mycobacterium Tuberculosis Pulmonary Infection. Tuberculosis (Edinb) (2004) 84(6):38796. doi: 10.1016/j.tube.2004.07.001

183. Taylor JL, Hattle JM, Dreitz SA, Troudt JM, Izzo LS, Basaraba RJ, et al. Role for Matrix Metalloproteinase 9 in Granuloma Formation During Pulmonary Mycobacterium Tuberculosis Infection. Infect Immun (2006) 74(11):613544. doi: 10.1128/IAI.02048-05

184. Harris JE, Nuttall RK, Elkington PT, Green JA, Horncastle DE, Graeber MB, et al. Monocyte-Astrocyte Networks Regulate Matrix Metalloproteinase Gene Expression and Secretion in Central Nervous System Tuberculosis In Vitro and In Vivo. J Immunol (2007) 178(2):1199-207. doi: 10.4049/ jimmunol.178.2.1199

185. Matsuura E, Umehara F, Hashiguchi T, Fujimoto N, Okada Y, Osame M. Marked Increase of Matrix Metalloproteinase 9 in Cerebrospinal Fluid of Patients With Fungal or Tuberculous Meningoencephalitis. J Neurol Sci (2000) 173(1):45-52. doi: 10.1016/S0022-510X(99)00303-2

186. Price NM, Farrar J, Tran TT, Nguyen TH, Tran TH, Friedland JS. Identification of a Matrix-Degrading Phenotype in Human Tuberculosis In Vitro and In Vivo. J Immunol (2001) 166(6):4223-30. doi: 10.4049/ jimmunol.166.6.4223

187. Lee KY, Kim EH, Yang WS, Ryu H, Cho SN, Lee BI, et al. Persistent Increase of Matrix Metalloproteinases in Cerebrospinal Fluid of Tuberculous Meningitis. J Neurol Sci (2004) 220(1-2):73-8. doi: 10.1016/j.jns.2004.02.008

188. Mailankody S, Dangeti GV, Soundravally R, Joseph NM, Mandal J, Dutta TK, et al. Cerebrospinal Fluid Matrix Metalloproteinase 9 Levels, Blood-
Brain Barrier Permeability, and Treatment Outcome in Tuberculous Meningitis. PLoS One (2017) 12(7):e0181262. doi: 10.1371/ journal.pone.0181262

189. Li YJ, Wilkinson KA, Wilkinson RJ, Figaji AA, Rohlwink UK. Elevated Matrix Metalloproteinase Concentrations Offer Novel Insight Into Their Role in Pediatric Tuberculous Meningitis. J Pediatr Infect Dis Soc (2020) 9 (1):82-6. doi: 10.1093/jpids/piy141

190. Majeed S, Singh P, Sharma N, Sharma S. Title: Role of Matrix Metalloproteinase -9 in Progression of Tuberculous Meningitis: A Pilot Study in Patients at Different Stages of the Disease. BMC Infect Dis (2016) 16 (1):722. doi: 10.1186/s12879-016-1953-9

191. Thwaites GE, Simmons CP, Than Ha Quyen N, Thi Hong Chau T, Phuong Mai P, Thi Dung N, et al. Pathophysiology and Prognosis in Vietnamese Adults With Tuberculous Meningitis. J Infect Dis (2003) 188(8):1105-15. doi: $10.1086 / 378642$

192. Rai D, Garg RK, Mahdi AA, Jain A, Verma R, Tripathi AK, et al. Cerebrospinal Fluid Cytokines and Matrix Metalloproteinases in Human Immunodeficiency Seropositive and Seronegative Patients of Tuberculous Meningitis. Ann Indian Acad Neurol (2014) 17(2):171-8. doi: 10.4103/09722327.132617

193. Rohlwink UK, Walker NF, Ordonez AA, Li YJ, Tucker EW, Elkington PT, et al. Matrix Metalloproteinases in Pulmonary and Central Nervous System Tuberculosis-A Review. Int J Mol Sci (2019) 20(6):1350. doi: 10.3390/ ijms 20061350

194. Price NM, Gilman RH, Uddin J, Recavarren S, Friedland JS. Unopposed Matrix Metalloproteinase-9 Expression in Human Tuberculous Granuloma and the Role of TNF-Alpha-Dependent Monocyte Networks. J Immunol (2003) 171(10):5579-86. doi: 10.4049/jimmunol.171.10.5579

195. Green JA, Dholakia S, Janczar K, Ong CW, Moores R, Fry J, et al. Mycobacterium Tuberculosis-Infected Human Monocytes Down-Regulate Microglial MMP-2 Secretion in CNS Tuberculosis via TNFalpha, NFkappaB, P38 and Caspase 8 Dependent Pathways. J Neuroinflamm (2011) 8:46. doi: 10.1186/1742-2094-8-46

196. Brilha S, Sathyamoorthy T, Stuttaford LH, Walker NF, Wilkinson RJ, Singh S, et al. Early Secretory Antigenic Target-6 Drives Matrix Metalloproteinase10 Gene Expression and Secretion in Tuberculosis. Am J Respir Cell Mol Biol (2017) 56(2):223-32. doi: 10.1165/rcmb.2016-0162OC

197. Tadokera R, Meintjes GA, Wilkinson KA, Skolimowska KH, Walker N, Friedland JS, et al. Matrix Metalloproteinases and Tissue Damage in HIVTuberculosis Immune Reconstitution Inflammatory Syndrome. Eur J Immunol (2014) 44(1):127-36. doi: 10.1002/eji.201343593

198. Tai MS, Viswanathan S, Rahmat K, Nor HM, Kadir KAA, Goh KJ, et al. Cerebral Infarction Pattern in Tuberculous Meningitis. Sci Rep (2016) 6:38802. doi: 10.1038/srep38802

199. Misra UK, Kalita J, Maurya PK. Stroke in Tuberculous Meningitis. J Neurol Sci (2011) 303(1-2):22-30. doi: 10.1016/j.jns.2010.12.015

200. Springer P, Swanevelder S, van Toorn R, van Rensburg AJ, Schoeman J. Cerebral Infarction and Neurodevelopmental Outcome in Childhood Tuberculous Meningitis. Eur J Paediatr Neurol (2009) 13(4):343-9. doi: 10.1016/j.ejpn.2008.07.004

201. Zhang L, Zhang X, Li H, Chen G, Zhu M. Acute Ischemic Stroke in Young Adults With Tuberculous Meningitis. BMC Infect Dis (2019) 19(1):362. doi: 10.1186/s12879-019-4004-5

202. Chatterjee D, Radotra BD, Vasishta RK, Sharma K. Vascular Complications of Tuberculous Meningitis: An Autopsy Study. Neurol India (2015) 63 (6):926-32. doi: 10.4103/0028-3886.170086

203. Soni N, Kumar S, Shimle A, Ora M, Bathla G, Mishra P. Cerebrovascular Complications in Tuberculous Meningitis-A Magnetic Resonance Imaging Study in 90 Patients From a Tertiary Care Hospital. Neuroradiol J (2020) 33 (1):3-16. doi: 10.1177/1971400919881188

204. Sharma S, Goyal MK, Sharma K, Modi M, Sharma M, Khandelwal N, et al. Cytokines do Play a Role in Pathogenesis of Tuberculous Meningitis: A Prospective Study From a Tertiary Care Center in India. J Neurol Sci (2017) 379:131-6. doi: 10.1016/j.jns.2017.06.001

205. Rohlwink UK, Mauff K, Wilkinson KA, Enslin N, Wegoye E, Wilkinson RJ, et al. Biomarkers of Cerebral Injury and Inflammation in Pediatric Tuberculous Meningitis. Clin Infect Dis (2017) 65(8):1298-307. doi: $10.1093 / \mathrm{cid} / \mathrm{cix} 540$ 
206. Manyelo CM, Chegou NN, Seddon JA, Snyders CI, Mutavhatsindi H, Manngo PM, et al. Serum and Cerebrospinal Fluid Host Proteins Indicate Stroke in Children With Tuberculous Meningitis. PLoS One (2021) 16(4): e0250944. doi: 10.1371/journal.pone.0250944

207. Schoeman J, Mansvelt E, Springer P, van Rensburg AJ, Carlini S, Fourie E. Coagulant and Fibrinolytic Status in Tuberculous Meningitis. Pediatr Infect Dis J (2007) 26(5):428-31. doi: 10.1097/01.inf.0000261126.60283.cf

208. Jimenez-Alcazar M, Rangaswamy C, Panda R, Bitterling J, Simsek YJ, Long AT, et al. Host DNases Prevent Vascular Occlusion by Neutrophil Extracellular Traps. Science (2017) 358(6367):1202-6. doi: 10.1126/ science.aam 8897

209. Hakkim A, Furnrohr BG, Amann K, Laube B, Abed UA, Brinkmann V, et al. Impairment of Neutrophil Extracellular Trap Degradation is Associated With Lupus Nephritis. Proc Natl Acad Sci U S A (2010) 107(21):9813-8. doi: 10.1073/pnas.0909927107

210. Farrera C, Fadeel B. Macrophage Clearance of Neutrophil Extracellular Traps is a Silent Process. J Immunol (2013) 191(5):2647-56. doi: 10.4049/ jimmunol.1300436

211. Brill A, Fuchs TA, Savchenko AS, Thomas GM, Martinod K, De Meyer SF, et al. Neutrophil Extracellular Traps Promote Deep Vein Thrombosis in Mice. J Thromb Haemost (2012) 10(1):136-44. doi: 10.1111/j.15387836.2011.04544.x

212. Maugeri N, Campana L, Gavina M, Covino C, De Metrio M, Panciroli C, et al. Activated Platelets Present High Mobility Group Box 1 to Neutrophils, Inducing Autophagy and Promoting the Extrusion of Neutrophil Extracellular Traps. J Thromb Haemost (2014) 12(12):2074-88. doi: $10.1111 /$ jth. 12710

213. von Bruhl ML, Stark K, Steinhart A, Chandraratne S, Konrad I, Lorenz M, et al. Monocytes, Neutrophils, and Platelets Cooperate to Initiate and Propagate Venous Thrombosis in Mice In Vivo. J Exp Med (2012) 209 (4):819-35. doi: 10.1084/jem.20112322

214. McDonald B, Davis RP, Kim SJ, Tse M, Esmon CT, Kolaczkowska E, et al. Platelets and Neutrophil Extracellular Traps Collaborate to Promote Intravascular Coagulation During Sepsis in Mice. Blood (2017) 129 (10):1357-67. doi: 10.1182/blood-2016-09-741298

215. Laridan E, Denorme F, Desender L, Francois O, Andersson T, Deckmyn H, et al. Neutrophil Extracellular Traps in Ischemic Stroke Thrombi. Ann Neurol (2017) 82(2):223-32. doi: 10.1002/ana.24993

216. Thalin C, Hisada Y, Lundstrom S, Mackman N, Wallen H. Neutrophil Extracellular Traps: Villains and Targets in Arterial, Venous, and CancerAssociated Thrombosis. Arterioscler Thromb Vasc Biol (2019) 39(9):172438. doi: 10.1161/ATVBAHA.119.312463

217. Gould TJ, Vu TT, Swystun LL, Dwivedi DJ, Mai SH, Weitz JI, et al. Neutrophil Extracellular Traps Promote Thrombin Generation Through PlateletDependent and Platelet-Independent Mechanisms. Arterioscler Thromb Vasc Biol (2014) 34(9):1977-84. doi: 10.1161/ATVBAHA.114.304114

218. Carestia A, Kaufman T, Schattner M. Platelets: New Bricks in the Building of Neutrophil Extracellular Traps. Front Immunol (2016) 7:271. doi: 10.3389/ fimmu.2016.00271

219. Brill A, Fuchs TA, Chauhan AK, Yang JJ, De Meyer SF, Kollnberger M, et al. Von Willebrand Factor-Mediated Platelet Adhesion is Critical for Deep Vein Thrombosis in Mouse Models. Blood (2011) 117(4):1400-7. doi: 10.1182/ blood-2010-05-287623

220. Etulain J, Martinod K, Wong SL, Cifuni SM, Schattner M, Wagner DD. PSelectin Promotes Neutrophil Extracellular Trap Formation in Mice. Blood (2015) 126(2):242-6. doi: 10.1182/blood-2015-01-624023

221. Hamzeh-Cognasse H, Damien P, Chabert A, Pozzetto B, Cognasse F, Garraud O. Platelets and Infections - Complex Interactions With Bacteria. Front Immunol (2015) 6:82. doi: 10.3389/fimmu.2015.00082

222. van der Maten E, de Bont CM, de Groot R, de Jonge MI, Langereis JD, van der Flier M. Alternative Pathway Regulation by Factor H Modulates Streptococcus Pneumoniae Induced Proinflammatory Cytokine Responses by Decreasing C5a Receptor Crosstalk. Cytokine (2016) 88:281-6. doi: 10.1016/j.cyto.2016.09.025

223. Noubouossie DF, Whelihan MF, Yu YB, Sparkenbaugh E, Pawlinski R, Monroe DM, et al. In Vitro Activation of Coagulation by Human Neutrophil DNA and Histone Proteins But Not Neutrophil Extracellular Traps. Blood (2017) 129(8):1021-9. doi: 10.1182/blood-2016-06-722298
224. Semeraro F, Ammollo CT, Morrissey JH, Dale GL, Friese P, Esmon NL, et al. Extracellular Histones Promote Thrombin Generation Through PlateletDependent Mechanisms: Involvement of Platelet TLR2 and TLR4. Blood (2011) 118(7):1952-61. doi: 10.1182/blood-2011-03-343061

225. Kambas K, Mitroulis I, Apostolidou E, Girod A, Chrysanthopoulou A, Pneumatikos I, et al. Autophagy Mediates the Delivery of Thrombogenic Tissue Factor to Neutrophil Extracellular Traps in Human Sepsis. PLoS One (2012) 7(9):e45427. doi: 10.1371/journal.pone.0045427

226. Massberg S, Grahl L, von Bruehl ML, Manukyan D, Pfeiler S, Goosmann C, et al. Reciprocal Coupling of Coagulation and Innate Immunity via Neutrophil Serine Proteases. Nat Med (2010) 16(8):887-96. doi: 10.1038/nm.2184

227. Sambrano GR, Huang W, Faruqi T, Mahrus S, Craik C, Coughlin SR. Cathepsin G Activates Protease-Activated Receptor-4 in Human Platelets. J Biol Chem (2000) 275(10):6819-23. doi: 10.1074/jbc.275.10.6819

228. Shiogama K, Onouchi T, Mizutani Y, Sakurai K, Inada K, Tsutsumi Y. Visualization of Neutrophil Extracellular Traps and Fibrin Meshwork in Human Fibrinopurulent Inflammatory Lesions: I. Light Microscopic Study. Acta Histochem Cytochem (2016) 49(4):109-16. doi: 10.1267/ahc.16015

229. Onouchi T, Shiogama K, Mizutani Y, Takaki T, Tsutsumi Y. Visualization of Neutrophil Extracellular Traps and Fibrin Meshwork in Human Fibrinopurulent Inflammatory Lesions: III. Correlative Light and Electron Microscopic Study. Acta Histochem Cytochem (2016) 49(5):141-7. doi: $10.1267 /$ ahc. 16028

230. Onouchi T, Shiogama K, Matsui T, Mizutani Y, Sakurai K, Inada K, et al. Visualization of Neutrophil Extracellular Traps and Fibrin Meshwork in Human Fibrinopurulent Inflammatory Lesions: II. Ultrastructural Study. Acta Histochem Cytochem (2016) 49(4):117-23. doi: 10.1267/ahc.16016

231. Fuchs TA, Brill A, Duerschmied D, Schatzberg D, Monestier M, Myers DD Jr, et al. Extracellular DNA Traps Promote Thrombosis. Proc Natl Acad Sci U S A (2010) 107(36):15880-5. doi: 10.1073/pnas.1005743107

232. Thammavongsa V, Kim HK, Missiakas D, Schneewind O. Staphylococcal Manipulation of Host Immune Responses. Nat Rev Microbiol (2015) 13 (9):529-43. doi: 10.1038/nrmicro3521

233. Thwaites G, Fisher M, Hemingway C, Scott G, Solomon T, Innes J, et al. British Infection Society Guidelines for the Diagnosis and Treatment of Tuberculosis of the Central Nervous System in Adults and Children. J Infect (2009) 59(3):167-87. doi: 10.1016/j.jinf.2009.06.011

234. van Toorn R, Schaaf HS, Laubscher JA, van Elsland SL, Donald PR, Schoeman JF. Short Intensified Treatment in Children With DrugSusceptible Tuberculous Meningitis. Pediatr Infect Dis J (2014) 33(3):24852. doi: 10.1097/INF.0000000000000065

235. Thwaites GE, Lan NT, Dung NH, Quy HT, Oanh DT, Thoa NT, et al. Effect of Antituberculosis Drug Resistance on Response to Treatment and Outcome in Adults With Tuberculous Meningitis. J Infect Dis (2005) 192 (1):79-88. doi: 10.1086/430616

236. Donald PR. Cerebrospinal Fluid Concentrations of Antituberculosis Agents in Adults and Children. Tuberculosis (Edinb) (2010) 90(5):279-92. doi: 10.1016/j.tube.2010.07.002

237. Ruslami R, Ganiem AR, Dian S, Apriani L, Achmad TH, van der Ven AJ, et al. Intensified Regimen Containing Rifampicin and Moxifloxacin for Tuberculous Meningitis: An Open-Label, Randomised Controlled Phase 2 Trial. Lancet Infect Dis (2013) 13(1):27-35. doi: 10.1016/S1473-3099(12)70264-5

238. Heemskerk AD, Bang ND, Mai NT, Chau TT, Phu NH, Loc PP, et al. Intensified Antituberculosis Therapy in Adults With Tuberculous Meningitis. N Engl J Med (2016) 374(2):124-34. doi: 10.1056/NEJMoa1507062

239. Dian S, Yunivita V, Ganiem AR, Pramaesya T, Chaidir L, Wahyudi K, et al. Double-Blind, Randomized, Placebo-Controlled Phase II Dose-Finding Study To Evaluate High-Dose Rifampin for Tuberculous Meningitis. Antimicrob Agents Chemother (2018) 62(12). doi: 10.1128/AAC.01014-18

240. Schoeman JF, Van Zyl LE, Laubscher JA, Donald PR. Serial CT Scanning in Childhood Tuberculous Meningitis: Prognostic Features in 198 Cases. J Child Neurol (1995) 10(4):320-9. doi: 10.1177/088307389501000417

241. Ramachandran P, Duraipandian M, Nagarajan M, Prabhakar R, Ramakrishnan CV, Tripathy SP. Three Chemotherapy Studies of Tuberculous Meningitis in Children. Tubercle (1986) 67(1):17-29. doi: 10.1016/0041-3879(86)90028-0

242. Alarcon F, Escalante L, Perez Y, Banda H, Chacon G, Duenas G. Tuberculous Meningitis. Short Course of Chemotherapy. Arch Neurol (1990) 47 (12):1313-7. doi: 10.1001/archneur.1990.00530120057010 
243. Dian S, Hermawan R, van Laarhoven A, Immaculata S, Achmad TH, Ruslami R, et al. Brain MRI Findings in Relation to Clinical Characteristics and Outcome of Tuberculous Meningitis. PLoS One (2020) 15(11):e0241974. doi: 10.1371/journal.pone.0241974

244. Tsenova L, Singhal A. Effects of Host-Directed Therapies on the Pathology of Tuberculosis. J Pathol (2020) 250(5):636-46. doi: 10.1002/path.5407

245. Mai NT, Dobbs N, Phu NH, Colas RA, Thao LT, Thuong NT, et al. A Randomised Double Blind Placebo Controlled Phase 2 Trial of Adjunctive Aspirin for Tuberculous Meningitis in HIV-Uninfected Adults. Elife (2018) 7. doi: 10.7554/eLife.33478

246. Misra UK, Kalita J, Nair PP. Role of Aspirin in Tuberculous Meningitis: A Randomized Open Label Placebo Controlled Trial. J Neurol Sci (2010) 293(12):12-7. doi: 10.1016/j.jns.2010.03.025

247. Simmons CP, Thwaites GE, Quyen NT, Chau TT, Mai PP, Dung NT, et al. The Clinical Benefit of Adjunctive Dexamethasone in Tuberculous Meningitis is Not Associated With Measurable Attenuation of Peripheral or Local Immune Responses. J Immunol (2005) 175(1):579-90. doi: 10.4049/ jimmunol.175.1.579

248. Misra UK, Kalita J, Kumar M. Safety and Efficacy of Fludrocortisone in the Treatment of Cerebral Salt Wasting in Patients With Tuberculous Meningitis: A Randomized Clinical Trial. JAMA Neurol (2018) 75 (11):1383-91. doi: 10.1001/jamaneurol.2018.2178

249. Cresswell FV, Musubire AK, Johansson Århem KM. “Chapter 6 - Treatment Guidelines for Tuberculosis and Tuberculous Meningitis”. In: JH-C Chin, editor. Tuberculous Meningitis. San Diego: Academic Press (2020). p. 67-101.

250. Miow QH, Vallejo AF, Wang Y, Hong JM, Bai C, Teo FS, et al. Doxycycline Host-Directed Therapy in Human Pulmonary Tuberculosis. J Clin Invest (2021) 131(15). doi: 10.1172/JCI141895

251. Majeed S, Radotra BD, Sharma S. Adjunctive Role of MMP-9 Inhibition Along With Conventional Anti-Tubercular Drugs Against Experimental Tuberculous Meningitis. Int J Exp Pathol (2016) 97(3):230-7. doi: 10.1111/ iep. 12191

252. Prasad K, Singh MB, Ryan H. Corticosteroids for Managing Tuberculous Meningitis. Cochrane Database Syst Rev (2016) 4:CD002244. doi: 10.1002/ 14651858.CD002244.pub4

253. Thwaites GE, Macmullen-Price J, Tran TH, Pham PM, Nguyen TD, Simmons CP, et al. Serial MRI to Determine the Effect of Dexamethasone on the Cerebral Pathology of Tuberculous Meningitis: An Observational Study. Lancet Neurol (2007) 6(3):230-6. doi: 10.1016/S1474-4422(07)70034-0

254. Torok ME. Tuberculous Meningitis: Advances in Diagnosis and Treatment. Br Med Bull (2015) 113(1):117-31. doi: 10.1093/bmb/ldv003

255. Suarez I, Gruell H, Heyckendorf J, Funger S, Lichtenstein T, Jung N, et al. Intensified Adjunctive Corticosteroid Therapy for CNS Tuberculomas. Infection (2020) 48(2):289-93. doi: 10.1007/s15010-019-01378-3

256. Afghani B, Lieberman JM. Paradoxical Enlargement or Development of Intracranial Tuberculomas During Therapy: Case Report and Review. Clin Infect Dis (1994) 19(6):1092-9. doi: 10.1093/clinids/19.6.1092

257. Anuradha HK, Garg RK, Sinha MK, Agarwal A, Verma R, Singh MK, et al. Intracranial Tuberculomas in Patients With Tuberculous Meningitis:
Predictors and Prognostic Significance. Int J Tuberc Lung Dis (2011) 15 (2):234-9.

258. Mazodier K, Bernit E, Faure V, Rovery C, Gayet S, Seux V, et al. [Central Nervous Tuberculosis in Patients non-VIH: Seven Case Reports]. Rev Med Interne (2003) 24(2):78-85. doi: 10.1016/S0248-8663(02)00715-4

259. Schoeman JF, Janse van Rensburg A, Laubscher JA, Springer P. The Role of Aspirin in Childhood Tuberculous Meningitis. J Child Neurol (2011) 26 (8):956-62. doi: 10.1177/0883073811398132

260. Richman IB, Owens DK. Aspirin for Primary Prevention. Med Clin North Am (2017) 101(4):713-24. doi: 10.1016/j.mcna.2017.03.004

261. Botting RM. Vane's Discovery of the Mechanism of Action of Aspirin Changed Our Understanding of its Clinical Pharmacology. Pharmacol Rep (2010) 62(3):518-25. doi: 10.1016/S1734-1140(10)70308-X

262. Raju N, Sobieraj-Teague M, Hirsh J, O'Donnell M, Eikelboom J. Effect of Aspirin on Mortality in the Primary Prevention of Cardiovascular Disease. Am J Med (2011) 124(7):621-9. doi: 10.1016/j.amjmed.2011.01.018

263. Ortiz-Munoz G, Mallavia B, Bins A, Headley M, Krummel MF, Looney MR. Aspirin-Triggered 15-Epi-Lipoxin A4 Regulates Neutrophil-Platelet Aggregation and Attenuates Acute Lung Injury in Mice. Blood (2014) 124 (17):2625-34. doi: 10.1182/blood-2014-03-562876

264. Kroesen VM, Rodriguez-Martinez P, Garcia E, Rosales Y, Diaz J, MartinCespedes M, et al. A Beneficial Effect of Low-Dose Aspirin in a Murine Model of Active Tuberculosis. Front Immunol (2018) 9:798. doi: 10.3389/ fimmu.2018.00798

265. Lapponi MJ, Carestia A, Landoni VI, Rivadeneyra L, Etulain J, Negrotto S, et al. Regulation of Neutrophil Extracellular Trap Formation by Anti-Inflammatory Drugs. J Pharmacol Exp Ther (2013) 345(3):430-7. doi: 10.1124/jpet.112.202879

266. Hamid U, Krasnodembskaya A, Fitzgerald M, Shyamsundar M, Kissenpfennig A, Scott C, et al. Aspirin Reduces LipopolysaccharideInduced Pulmonary Inflammation in Human Models of ARDS. Thorax (2017) 72(11):971-80. doi: 10.1136/thoraxjnl-2016-208571

Conflict of Interest: CO received speaking fees from Qiagen outside this work. The authors declare that the research was conducted in the absence of any commercial or financial relationships that could be construed as a potential conflict of interest.

Publisher's Note: All claims expressed in this article are solely those of the authors and do not necessarily represent those of their affiliated organizations, or those of the publisher, the editors and the reviewers. Any product that may be evaluated in this article, or claim that may be made by its manufacturer, is not guaranteed or endorsed by the publisher.

Copyright (c) 2022 Poh, Loh, Friedland and Ong. This is an open-access article distributed under the terms of the Creative Commons Attribution License (CC BY). The use, distribution or reproduction in other forums is permitted, provided the original author(s) and the copyright owner(s) are credited and that the original publication in this journal is cited, in accordance with accepted academic practice. No use, distribution or reproduction is permitted which does not comply with these terms. 